\title{
LA “EXCEPCIÓN DE CONTRATO NO CUMPLIDO ADECUADA O REGULARMENTE" Y SU RÉGIMEN EN EL DERECHO CIVIL ESPAÑOL
}

[The "Exception of a Non-Fulfilled Contract, Either on a Proper or Regular Basis" and Its Regime in the Spanish Civil Law]

\section{Sebastián Bozzo Hauri*}

Universidad Autónoma de Chile, Santiago

\section{RESUMEN}

El trabajo analiza la disciplina de la excepción de contrato no cumplido adecuada o regularmente, en el ámbito de los contratos que contienen obligaciones recíprocas o sinalagmáticas, sobre la base de la doctrina y la jurisprudencia españolas.

Palabras clave

Excepción de contrato no cumplido adecuada o regularmente - Excepción de contrato no cumplido - Acción de cumplimiento.
Abstract

This work analyzes the discipline of the exception of non-fulfilled contracts either on a proper properly or regular basis, in the scope of contracts that have mutual or synallagmatic obligations based on the Spanish doctrine and jurisprudence.

\section{KeYwords}

Exception of non-fulfilled contracts either on a proper or regular basis- Exception of a non-fulfilled contract - Enforcement Action.

RECIBIDO el 13 de enero y ACEPTADo el 2 de mayo de 2014

* Dirección postal: Pedro de Valdivia 641, Providencia, Santiago, Chile. Mail: sebastian.bozzo@uautonoma.cl 


\section{INTRODUCCIÓN}

La excepción de contrato no cumplido adecuada o regularmente es una variante de la excepción de contrato no cumplido, creada según algunos autores en el siglo XVIII ${ }^{1}$, que tiene por finalidad proteger a los contratantes que ven vulnerado la ejecución exacta de su obligación y cuyo principal objetivo es enervar el pago de la contraprestación hasta que los defectos hayan sido corregidos o la parte de la prestación no ejecutada se concluya.

En términos generales, se puede afirmar que el cumplimiento es defectuoso o inexacto en todos aquellos supuestos en los que la prestación realizada por el deudor, al cumplir su obligación, no contiene los requisitos que integraban su contenido o prestación. En consecuencia, no queda satisfecho el interés del acreedor, ni puede en puridad decirse que el deudor queda liberado, y por ello extinguida la obligación ${ }^{2}$.

De esta forma, si se relacionan los artículos 1157, 1166 y $1169^{3}$ CCEsp., el acreedor no está obligado a recibir cosa distinta de la pactada, ni un cumplimiento parcial, como tampoco se deberá conformar con una prestación que no se ajuste a lo convenido, ni existe precepto legal alguno que a ello le obligue bajo reserva de exigir su corrección. Así, el cumplimiento ha de

${ }^{1}$ Traviesas, Miguel, Obligaciones reciprocas, en Revista de Derecho Privado, 192 (1929), pp. 331.

${ }^{2}$ Beltrán de Heredia y Onis, Pablo, El incumplimiento de las obligaciones (Madrid, Edersa, Editoriales de Derecho Reunidas, 1990), p. 58. Para DíEz-Picazo, Luis, Fundamentos del Derecho civil patrimonial (Madrid, Editorial Civitas, 1996), II, p. 666, la diferencia más importante que esta figura ofrece frente al incumplimiento definitivo y a la mora es que, así como en estos últimos casos se ha producido una omisión total de la prestación, en el nuestro existe un comportamiento positivo del deudor dirigido a cumplir, que, sin embargo, no se ajusta a los términos del programa establecido en el acto de constitución de la relación obligatoria. Dicho más claramente, no es que el deudor no haya hecho nada, sino que lo que ha hecho está mal hecho. En este mismo sentido: Martínez Calcerrada, Luis, Cumplimiento defectuoso de la prestación, en Revista Critica de Derecho Inmobiliario (1976), pp. 1.348.

${ }^{3} \mathrm{El}$ artículo 1157 indica que "No se entenderá pagada una deuda sino cuando completamente se hubiese entregado la cosa o hecho la prestación en que la obligación consistía". El artículo 1166 por su parte señala: "El deudor de una cosa no puede obligar a su acreedor a que reciba otra diferente, aun cuando fuere de igual o mayor valor que la debida./ Tampoco en las obligaciones de hacer podrá ser sustituido un hecho por otro contra la voluntad del acreedor". Por último, el artículo 1169 dice: "A menos que el contrato expresamente lo autorice, no podrá compelerse al acreedor a recibir parcialmente las prestaciones en que consista la obligación. Sin embargo, cuando la deuda tuviere una parte liquida y otra ilíquida, podrá exigir el acreedor y hacer el deudor el pago de la primera sin esperar a que se liquide la segunda". 
sujetarse en todas sus modalidades al programa de prestación previsto al constituirse la obligación para tener por cumplida ésta.

Como indica la sentencia del Tribunal Supremo español de 3 de marzo de 1979, cumplir una obligación, es satisfacer el interés del acreedor de una manera exacta, "íntegra y puntual".

Ante el cumplimiento defectuoso o inexacto de la prestación en las relaciones obligatorias sinalagmáticas, el acreedor dispone de diferentes instrumentos jurídicos para exigir el correcto cumplimiento. Estas son la acción de cumplimiento, ya sea a través de la reparación in natura o por medio del pago de una suma de dinero que permita compensar dicho defecto o la solicitud de reducción del precio debido.

Esta última acción se ejercita normalmente por vía reconvencional una vez ejercitada la exceptio non rite adimpleti contractus. Además, existe la posibilidad de solicitar la resolución ${ }^{4}$, pudiéndose acompañar todas estas acciones de la solicitud de que se reparen los daños y perjuicios ocasionados.

En principio, la exceptio no es un medio que sirva por sí mismo para obtener el cumplimiento de la prestación, sino que más bien para detener la demanda de cumplimiento. No obstante, a veces es necesario su ejercicio para, por ejemplo, solicitar la reducción del precio a través de la demanda reconvencional. Esto es así, debido a que la exceptio será la defensa idónea que justifique luego, en la demanda reconvencional, la solicitud de reducción del precio, cuestión que, como sabemos, se encuentra conectada a la negación de cumplimiento que se justifica en el incumplimiento del demandante.

\section{CONFIgURACIÓN DE LA “EXCEPTIO NON RITE ADIMPLETI CONTRACTUS"}

La exceptio se suele fundamentar en cumplimientos de tipo parcial o defectuoso. Ambos fundamentos presentan un cierto grado de complejidad. El primero se halla en la evaluación de la proporcionalidad, entre la porción que resta por cumplir al demandante y la entidad de la propia prestación del excipens. A su vez, el incumplimiento defectuoso presenta la dificultad de determinar en qué grado la prestación se aleja en cuanto a calidad, el lugar o cualquier otra circunstancia pactada en interés del acreedor.

Es plausible entender que lo que quiere el contratante es obtener la totalidad de las prestaciones del otro, y sería desconocer su voluntad obligarle

${ }^{4}$ En los casos de prestación defectuosa, la resolución posee un alcance excepcional y requiere, de acuerdo con las directrices jurisprudenciales, una frustración total del contrato. En particular, que la prestación defectuosa no sea útil por no servir al fin al que se le había destinado; o que el interés del acreedor en la resolución sea atendible, por no aparecer la resolución como abusiva o como contraria a la buena fe. 
a cumplir su obligación cuando solamente recibe una parte de lo que se le prometió, o lo cumplido no se ajusta con lo acordado por las partes del contrato. Además, no se puede olvidar que cuando el deudor se aparta de lo convenido y no cumple aquello que prometió, esto es, no ejecuta la prestación en los términos convenidos, conlleva la infracción del artículo $1091^{5}$ CCEsp., que consagra el principio "pacta sunt servanda", es decir, que lo pactado debe cumplirse, ya que las obligaciones que nacen de los contratos tienen fuerza de ley para las partes ${ }^{6}$.

Traviesas explica la figura señalando: “[...] Puede ocurrir también que, en las obligaciones recíprocas, uno de los obligados realice el cumplimiento de la prestación que le incumbe en forma que no sea la forma debida. El otro obligado puede negarse, entonces a realizar la contraprestación que debe, mientras la parte contraria no cumple en la forma debida. A esta excepción se le da el nombre de exceptio non rite adimpleti contractus o el de exceptio non debito modo adimpleti contractus [...]" 7 .

Al respecto, Fernandez Hierro distingue entre la excepción de cumplimiento inadecuado o defectuoso de la excepción de incumplimiento contractual, y en este sentido señala que “[...] se distinguen dos clases de excepciones paralelas: la exceptio non adimpleti contractus y la exceptio non rite adimpleti contractus. La diferencia entre ambas reside en que la exceptio non adimpleti contractus supone un incumplimiento total por la otra parte, mientras que la exceptio non rite adimpleti contractus sólo comporta un incumplimiento parcial o defectuoso"

Por su parte, Díez-Picazo indica que "la exceptio non rite adimpleti contractus es una variante o una modalidad de la excepción general de incumplimiento. Cuando el demandante sólo ha cumplido la prestación a su cargo parcialmente o de manera defectuosa, el demandado puede rehusar su propia prestación hasta que la primera haya sido cumplida totalmente o

${ }^{5}$ El artículo 1091 precisa que "Las obligaciones que nacen de los contratos tienen fuer$z a$ de ley entre las partes contratantes, y deben cumplirse al tenor de los mismos".

${ }^{6}$ En este sentido, Martínez Calcerrada, Luis cit. (n. 2), p. 1.344; y Bercovitz Rodríguez-Cano, Rodrigo, Comentarios al Código Civil (Navarra, Aranzadi, 2001), p. 1.260, al señalar: "El artículo 1.091 es una plasmación, tal vez la más genuina, del dogma de la autonomía de la voluntad y del principio "pacta sunt servanda". Sin embargo, esta exaltación del contrato, elevándolo a la categoría de verdadera "lex privata”, no alcanza hasta el punto de convertirlo en fuente de Derecho objetivo, sino a lo sumo de obligaciones, o lo que es lo mismo de derechos subjetivos".

${ }^{7}$ Traviesas, Miguel, cit. (n. 1), p. 337.

${ }^{8}$ Fernández Hierro, José Manuel, La exceptio non adimpleti contractus, en Estudios de Deusto (1995), p. 77. 
ejecutada de forma rigurosa, rectificando de modo pertinente los defectos que la prestación presentaba"'.

Puig Brutau nos señala: "[...] puede suceder que la falta de cumplimiento simultáneo sólo sea parcial o que la prestación sea defectuosa. En principio es procedente la excepción de falta de un cumplimiento regular y en este sentido se habla de la exceptio non rite adimpleti contractus, mediante la cual el demandado podrá negarse a efectuar la prestación que le incumbe hasta que la parte actora haya cumplido la suya de la manera convenida" ${ }^{10}$.

La jurisprudencia española, por su parte, también reconoce de manera

${ }^{9}$ Díez-Picazo, Luis, cit. (n. 2), p. 694. Enneccerus, Ludwing, Derecho de obligaciones (15 revisión por Henrich Lehmann, traducción de Blas Pérez González y José Alguer, 2a edición, Barcelona, Bosh, 1954-1999), II, p. 167, n. 2, señala: “Una excepción igual, que en este caso se denomina excepción de contrato no cumplido pertinentemente (exceptio non rite adimpleti contractus) le corresponde al deudor, cuando el acreedor sólo hs cumplido en parte, o sólo de un modo defectuoso, hasta tanto que la prestación sea completada o mejorada de la manera pertinente". HedEMANN, Justus Wilhelm, Tratado de Derecho civil (traducción de Jaime Santos Briz, Madrid, Revista de derecho privado, 1956), III, p. 103, señala: "En el mismo grado que el incumplimiento de la prestación hemos de colocar la entrega de una prestación que no corresponda. En este caso la terminología científica coloca junto a la exceptio non impleti contractus, la llamada exceptio non rite impleti contractus, que concede a la parte contratante demandada la misma posibilidad de defensa. En este caso no entra en consideración la culpabilidad de la parte primeramente obligada a cumplir la prestación”. En el mismo sentido, la sentencia de la Audiencia Provincial de Toledo, de 25 de febrero de 1998 (AC 1998\3722), señala que: "La excepción de cumplimiento inadecuado o de contrato no cumplido regularmente constituye, como se ha visto una variante de la excepción general de incumplimiento contractual, con idéntica apoyatura legal, por lo que, cuando el demandante sólo ha cumplido la prestación a su cargo parcialmente o de manera defectuosa, el demandado puede rehusar su propia prestación hasta que la primera haya sido cumplida totalmente o ejecutada de forma rigurosa, rectificando de modo pertinente los defectos que la prestación presentaba. En una y otra, la ejecución de la prestación reclamada al demandado queda en suspenso, diferida o condicionada a la total y exacta realización simultanea por el actor de la prestación que correlativamente le incumbe".

${ }^{10}$ Puig Brutau, José, Fundamentos de Derecho civil (Barcelona, Bosch, 1988), I, p. 116. Por su parte, García Amigo, Manuel, Teoria general de las obligaciones y contratos. Lecciones de derecho civil (Madrid, McGraw-Hill/Interamericana de España, 1995), II, p. 534, se refiere a la exceptio non rite adimpleti contractus señalando: "Una modalidad de la excepción de contrato no cumplido, es la misma excepción para los casos en que no se trate de incumplimiento total por la otra parte, sino sólo de incumplimiento parcial, o defectuoso o tardío cumplimiento". Indicando luego que: “[...] igualmente ha sido admitida por la jurisprudencia bajo el nombre de exceptio non rite adimpleti contractus, con el mismo efecto paralizante que legítima el retrasar el cumplimiento". Ahora bien, dice: "esta modalidad plantea el difícil problema de determinar qué grado de incumplimiento es suficiente para fundar la excepción: tratándose de obligaciones sinalagmáticas habría que acudir a los parámetros del art. 1124, a efectos de justificar 
contundente la figura de la excepción de incumplimiento parcial o defectuoso, reconociendo que aunque carezca de regulación expresa en el Código Civil español, se infiere de los artículos 1100,1154 y $1157^{11}$ del mismo texto legal ${ }^{12}$.

La sentencia del Tribunal Supremo español de 14 de junio de $2004^{13}$ reconoce la figura señalando: "[...] el orden de cumplimientos de las prestaciones debidas, como consecuencia de una relación de obligación sinalagmática, y la mutua condicionalidad e interdependencia que existe entre ellas, justifica que el deudor incumplidor le pueda oponer al deudor requerido de pago la llamada exceptio non adimpleti contractus".

En términos más amplios se refiere la sentencia del Tribunal Supremo de 27 de marzo de $1991^{14}$, al indicar: "[...] los principios del respeto a la palabra dada y a la buena fe dieron lugar al nacimiento de dos acciones diferentes, una de contrato no cumplido, llamada non adimpleti contractus $y$ otra de contrato no cumplido adecuadamente en -cantidad, calidad, manera o tiempo-denominada exceptio non rite adimpleti contractus, acciones no reguladas expresamente en nuestro ordenamiento juridico, pero cuya existencia esta implicitamente admitida en diversos preceptos y han sido sancionada por la jurisprudencia”.

En definitiva, podemos señalar que ambas excepciones tienen por objetivo oponerse al cumplimiento exigido por el demandante, diferenciándose en los presupuesto de una y otra. Así, el presupuesto básico de la exceptio non adimpleti contractus supone que el actor no ha cumplido ni ofrecido su pres-

la resolución del contrato. La sentencia antes citada, de 27 de marzo de 1991, habla de "defectos de cierta importancia que impidan satisfacer el interés del acreedor/deudor".

${ }^{11}$ El artículo 1100 señala: "Incurren en mora los obligados a entregar o a hacer alguna cosa desde que el acreedor les exija judicial o extrajudicialmente el cumplimiento de su obligación. No será, sin embargo, necesaria la intimación del acreedor para que la mora exista:/ $1^{\circ}$ Cuando la obligación o la ley lo declaren asi expresamente./ $2^{\circ}$ Cuando de su naturaleza y circunstancias resulte que la designación de la época en que habia de entregarse la cosa o hacerse el servicio, fue motivo determinante para establecer la obligación./ En las obligaciones recíprocas ninguno de los obligados incurre en mora si el otro no cumple o no se allana a cumplir debidamente lo que le incumbe. Desde que uno de los obligados cumple su obligación, empieza la mora para el otro". El artículo 1154 precisa que "El Juez modificará equitativamente la pena cuando la obligación principal hubiera sido en parteo irregularmente cumplida por el deudor".

${ }^{12}$ En este sentido, las sentencias del Tribunal Supremo de 27 de marzo de 1992 (RJ 1992\2451) y de 30 de diciembre de 1997 (RJ 1997\9669).

${ }^{13} \mathrm{RJ} 2004 \backslash 3837$. En este mismo sentido, las sentencias del Tribunal Supremo de 22 de octubre de 1997 (RJ 1997\7410), 21 de marzo de 2001 (RJ 2001\4748), 17 de diciembre de 2002 (RJ 2002\1259) y 21 de marzo de 2003 (RJ 2003\2763) entre otras.

${ }^{14} \mathrm{RJ} 1991 \backslash 2451$. Últimamente se reconoce esta modalidad de excepción en las sentencias del Tribunal Supremo de 5 de noviembre de 2007 (RJ 2007\8646), 28 de mayo de 2009 (RJ 2009\4142) y 1 de octubre de 2010 (RJ 2010\7309). 
tación; la exceptio non rite adimpleti contractus supone que lo ha realizado, pero inexactamente, de manera parcial o defectuosa ${ }^{15}$.

Otra de las diferencias que se pueden advertir entre ambas excepciones es en materia del orden probatorio. En el evento de ejercerse la exceptio non adimpleti contractus y, por ende, caso de inejecución de la prestación, es el demandante quien debe probar el cumplimiento íntegro que se le cuestiona. En cambio, en caso de incumplimiento defectuoso, es al excipens a quien le incumbe la prueba de las diferencias o irregularidades que la prestación del actor presenta.

Esto último es así, debido a que es el demandado quien introduce en el debate procesal nuevos hechos obstativos del regular y exacto cumplimiento debido por el demandante, pretendiendo que dichos hechos impeditivos le exoneren de la obligación del pago del precio ${ }^{16}$.

\section{CONSAGRACIÓN LEGAL}

El apoyo legal de la exceptio non rite adimpleti contractus es similar al de la excepción de contrato no cumplido, pero no idéntico, como señalan algunas sentencias en la jurisprudencia ${ }^{17}$. No obstante, podemos señalar que los artículos 1100 y 1124 CCEsp. ${ }^{18}$ sirven de fundamento para ambas exceptio.

\footnotetext{
${ }^{15}$ Sentencia de la Audiencia Provincial de Toledo de 25 de febrero de 1998 (AC $1998 \backslash 3722)$.

${ }^{16}$ Sentencias del Tribunal Supremo de 16 de mayo de 1989 (RJ 1989\3766) y de 20 de noviembre de 1990 (RJ 1990\8262). La Sentencia de la Audiencia Provincial de Toledo, de 25 de febrero de 1998 (AC 1998\3722) nos señala respecto a las diferencias entre las exceptio non adimpleti contractus y non rite adimpleti contractus, lo siguiente: "Asi mismo, existe otra diferencia, en el orden probatorio, entre los casos de inejecución o ejecución incompleta y los de realización defectuosa de la prestación, puesto que, si el demandante corre, en los primeros, con la carga de probar el cumplimiento integro que se le cuestiona, es al demandado, en los segundos, a quien incumbe la prueba de las deficiencias o irregularidades que la prestación del actor presenta, en cuanto en ello el excipens no se limita a negar el cumplimiento de la obligación contraída por el demandante, sino que introduce en el debate procesal nuevos hechos obstativos del regular y exacto cumplimiento debido por éste". En este mismo sentido, las sentencias de la Audiencia Provincial de Girona, de 30 de marzo de 1999 (AC 1999\1117), de Madrid, de 8 de febrero de 2010 (AC 2010\463) indicando ésta última que: “[... bien entendido que dicha excepción debe ser probada por quien la alega por ser un hecho extintivo y enervador del efecto jurídico pretendido de contrario (art. 217.3 LEC). En el mismo sentido se pronuncia, por ejemplo, las S.S. de esta sección de 16 de marzo ó 23 febrero 2009 (PROV 2009, 170533)".

${ }^{17}$ En este sentido, las sentencias del Tribunal Supremo de 30 de diciembre de 1997 (RJ 1997\9669), 14 de julio de 2003 (RJ 2003\4635) y 22 de julio de 2008 (RJ $2008 \backslash 4617)$ entre otras y por su parte así lo ha entendido la SAP de Toledo de 25 de febrero de 1998 (AC 1998\3722).

${ }^{18} \mathrm{El}$ artículo 1124 se refiere a "La facultad de resolver las obligaciones se entiende
} 
Además existen otras disposiciones que sirven para apoyar únicamente la excepción de contrato no cumplido adecuadamente, como son los artículos 1154 y 1157 CCEsp. ${ }^{19}$

La primera norma citada, se refiere a la facultad que ostenta el juez de poder moderar la pena establecida en una cláusula penal cuando la obligación principal hubiera sido en parte o irregularmente cumplida por el deudor. El segundo artículo señalado, norma al pago, y establece que no se entenderá pagada una deuda sino cuando completamente se hubiese entregado la cosa o hecho la prestación en que la obligación consistía.

El Derecho francés, al igual que en el derecho español, no se consagra de forma expresa la exceptio non adimpleti contractus ni la rite non adimpleti contractus, existen no obstante, disposiciones que sirven de base para su aplicación. El artículo $1653 \mathrm{CCFr} .{ }^{20}$ permite al comprador suspender el pago del precio cuando ha sido perturbado o tiene fundados motivos de serlo por

implícita en las reciprocas, para el caso de que uno de los obligados no cumpliere lo que le incumbe. El perjudicado podrá escoger entre exigir el cumplimiento o la resolución de la obligación, con el resarcimiento de daños y abono de intereses en ambos casos. También podrá pedir la resolución, aun después de haber optado por el cumplimiento, cuando éste resultare imposible. El Tribunal decretará la resolución que se reclame, a no haber causas justificadas que la autoricen para señalar plazo. Esto se entiende sin perjuicio de los derechos de terceros adquirentes, con arreglo a los artículos 1.295 y 1.298 y a las disposiciones de la Ley Hipotecaria".

${ }^{19}$ Sentencias del Tribunal Supremo de 17 de abril de 1976 (RJ 1976\1811), 27 de marzo de 1991 (RJ 1991\2541), 30 de diciembre de 1997 (RJ 1997\9669) entre otras. Sobre el artículo 1154: Bercovitz Rodríguez-Cano, Rodrigo, cit. (n. 6), p. 1351, señala: "Se suele valorar como el precepto que impone la integridad de la prestación para que pueda considerarse realizado el pago [...]". Y agrega: "Una interpretación más amplia permite referirlo a la exigencia de exactitud de la prestación; dentro de cuyo concepto se incluye fundamentalmente, junto con la integridad, la identidad, además del cumplimiento en el tiempo (STS 10 de abril 1981 [RJ 1981, 1531]) y en el lugar debidos, y el modo de realización de la obligación". Señalando más adelante que: "La referencia del artículo 1.157 para exigir el cumplimiento de la obligación o las consecuencias derivadas del incumplimiento es frecuentemente ineludible o, al menos, útil, puesto que contiene la norma que garantiza genéricamente la adecuación del pago al contenido de la obligación. Para pedir la resolución de los contratos en aplicación del artículo 1.124 -vendedor que entrega una cosechadora con importantes desperfectos (STS 25 de noviembre 1967 [RJ 1967, 4769])- o del artículo 1.504 (STS 21 marzo 1996 [RJ 1996, 2230]). Para el ejercicio de la exceptio non rite adimpleti contractus (STS 27 marzo 1991 [RJ 1991, 2451]).

${ }^{20} \mathrm{El}$ artículo 1653 CCFr. señala: "Si el comprador fuere perturbado, o tuviere fundado motivo para temerlo, por una acción hipotecaria o reivindicatoria, podrá suspender el pago del precio hasta que el vendedor haya hecho cesar la perturbación, a no ser que éste prefiera dar fiador, o que se haya estipulado que el comprador habrá de pagar no obstante la perturbación". 
una acción hipotecaria o reivindicatoria. Por su parte, el artículo $1.722 \mathrm{del}$ mismo cuerpo legal se refiere a la hipótesis en que la cosa alquilada perece, lo que permite en parte al arrendatario reclamar una disminución del precio o la rescisión del contrato. Por último, también en materia de arrendamiento, el artículo 1726 CCFr.aplica la misma solución en el caso de que el locatario o arrendatario hayan sido perturbados en el disfrute de la cosa por una acción relativa a la propiedad del finado ${ }^{21}$.

Así en el Derecho español, al igual que en el Derecho francés, se establecen ciertas normas en el Código Civil y en otras leyes especiales que permite a una de las partes poder suspender su prestación por el riesgo de que se vea por uno u otro motivo frustrada la finalidad del contrato, tal como se ha revisado en el epígrafe que estudia el ejercicio de la exceptio ante el riesgo de incumplimiento.

\section{IV. ÁMBITO DE APLICACIÓN}

El ámbito de aplicación de la exceptio non rite adimpleti contractus es distinto que el de la exceptio non adimpleti contractus, pues el supuesto de aplicación debe ser un cumplimiento inadecuado y no un incumplimiento en el sentido propio.

Sin embargo, en la práctica y en el estudio de la jurisprudencia, se puede apreciar que el ejercicio de la excepción de cumplimiento inadecuado es más frecuente. Esto, debido a que la situación más común es el cumplimiento de las obligaciones que se contraen, pero con la salvedad que no siempre se ajustan en su totalidad a lo pactado.

El ejercicio de esta modalidad de excepción de contrato no cumplido debe sostenerse, a nuestro entender, en supuestos de cumplimiento parcial o defectuoso. Cualquiera de estas dos situaciones da origen a la excepción de contrato no cumplido adecuadamente ${ }^{22}$.

\section{Cumplimiento parcial.}

Entendemos que este tipo de cumplimiento se caracteriza por que sólo existe una o varias prestaciones ejecutadas conforme al contrato, quedando

\footnotetext{
${ }^{21}$ Capitant, Henri, De la causa de las obligaciones (traducción y notas de Tarragato y Contreras, Madrid, Góngora, 1928), p. 281.

${ }^{22}$ Traviesas, Miguel, cit. (n. 1), p. 337, señala: "El incumplimiento parcial, en mi entender, no es el cumplimiento debido, cuando no existe derecho para imponerlo al acreedor. Ni se cumple con cosa debida, cuando existen vicios o gravámenes, desconocidos por el acreedor, al perfeccionarse el contrato, que den derecho a su impugnación. $\mathrm{Ni}$ cuando la prestación no sea de las cualidades debidas. En estos supuestos podrá ser utilizada la e.n.r.a.c".
} 
por ejecutar otras prestaciones que no están aún realizadas, que hagan posible entender un contrato fielmente cumplido. Esta situación es propia de los contratos de arrendamiento de obra, cuando se encarga al contratista la ejecución de una faena y ésta no se ha completado del todo, existiendo aún partidas de la obra sin ejecutar o concluir.

Se debe tener presente que en aquellos contratos de obra en que pacte el valor por piezas ejecutadas ${ }^{23}$ o por unidades de medida ${ }^{24}$, algunas sentencias, como la de la Audiencia Provincial de Madrid de 25 de mayo de $2004^{25}$, ha entendido este tipo de contrato como una relación contractual cuyo precio se fija y satisface por cada unidad de medida o pieza ejecutada y entregada, del total de la obra a realizar. Así la obra por unidad de medida, el todo tiene una única, propia, absoluta y continua identidad cualitativa; mientras que la parte representa un concepto numérico o cuantitativo que se sustenta sólo sobre una razón de extensión o concreción, fijándose sobre cada unidad de medida un valor determinado que facilita su cobro de manera parcializada.

La sentencia del Tribunal Supremo español de 14 de abril de $1979^{26}$ manifiesta que "[...] no puede afirmarse con fundamento que las entregas y pagos parciales sean contrarios a la naturaleza del contrato de arrendamiento de obra, desde el momento en que el propio Código admite en el articulo 1592 la contratación de una obra por piezas o por medida, en cuyo supuesto el contratista puede exigir del comitente o dueño de la obra que las reciba por partes y que las pague en la misma proporción".

En efecto, es razonable entender que no será útil para el comitente oponer la exceptio non rite adimpleti contractus cuando se haya pactado un contrato de arrendamiento de obra por unidad de medida o por piezas ejecutadas. Ello es tal, pues si bien existe una única y global ejecución, éste vendrá a disgregarse en una serie de contratos parciales de arrendamiento de obra, de forma que cada uno de ellos tendrá por objeto la realización de una pieza o unidad o clase de obra total ${ }^{27}$.

A mayor abundamiento, el artículo $1592^{28}$ CCEsp. entiende que en un

${ }^{23}$ La sentencia del Tribunal Supremo de 7 de octubre de 1964 lo define como aquel contrato "cuyo objeto se compone de diversas partes separadas e independientes entre si".

${ }^{24} \mathrm{La}$ sentencia de la Audiencia Provincial de Alicante de 13 de noviembre de 2003 (JUR 2003\18854) recoge el mismo concepto que la sentencia del Tribunal Supremo de 7 de octubre de 1964.

${ }^{25}$ JUR 2004\259001.

${ }^{26} \mathrm{RJ} 1979 \backslash 1545$.

${ }^{27}$ En este sentido, la sentencia de la Audiencia Provincial de Alicante de 25 de mayo de 2004 (JUR 2004\259001).

${ }^{28}$ El artículo 1592 señala: "El que se obliga a hacer una obra por piezas o por medida, puede exigir del dueño que la reciba por partes y que la pague en proporción. Se presume aprobada y recibida la parte satisfecha". 
contrato de obra por piezas o por medida el contratista tiene el derecho de exigir al comitente que la reciba por partes y que la pague en proporción, presumiendo aprobada y recibida la parte satisfecha.

\section{Cumplimiento defectuoso.}

Por este tipo de incumplimiento podemos entender la situación en la que el deudor ha llevado a cabo unos actos dirigidos a cumplir, es decir, ha realizado una prestación, pero ésta no coincide enteramente o no se ajusta por completo con el programa o proyecto de prestación tal y como se encontraba establecido en el acto de constitución de la relación obligatoria ${ }^{29}$. En otras palabras, el deudor realiza una prestación que afirma que se ajusta a la obligación, sin que en realidad suceda así, es decir, cumple mal ${ }^{30}$.

En los términos expresados, este tipo de incumplimiento, por lo general, al no ajustarse a lo convenido perjudica el fin de la prestación y por consiguiente puede originar un determinado daño en el patrimonio del acreedor. Es decir, puede llegar a tener la misma importancia que un incumplimiento en el cual no se ha comenzado ni siquiera a cumplir con parte del contrato. Por esto, se entiende que al igual que otros tipos de incumplimiento (como la inejecución propiamente tal o la ejecución tardía), éste genera responsabilidad contractual, toda vez que es posible, como señalamos, que se produzca un daño al acreedor. En efecto, se podrá perseguir la responsabilidad según lo indicado en el artículo $1101^{31}$ CCEsp.

Para poder entender cuándo nos enfrentamos ante un incumplimiento defectuoso o irregular, es necesario distinguir entre obligaciones de medio y de resultado.

Cabanillas $^{32}$ afirma que en las obligaciones de resultado el criterio para determinar el correcto cumplimiento es la presencia del resultado, es decir, la satisfacción del interés primario del acreedor, la que determina el cumplimiento, defectuosidad o el incumplimiento. En cambio, como se analizará a continuación, el cumplimiento defectuoso o irregular de las obligaciones de medio o de actividad, se determinan en base al criterio de exactitud en el cumplimiento propio, inherente al contenido de la prestación, que consis-

${ }^{29}$ Martínez Calcerrada, Luis, cit. (n. 2), pp. 1,348 ss.; Díez-Picazo, Luis, cit. (n. 2), p. 671.

${ }^{30}$ Puig Brutau, José, cit. (n. 10), p. 424.

${ }^{31} \mathrm{El}$ artículo 1101 indica que "Quedan sujetos a la indemnización de los daños y perjuicios causados los que en el cumplimiento de sus obligaciones incurrieren en dolo, negligencia o morosidad, y los que de cualquier modo contravinieren al tenor de aquéllas".

${ }^{32}$ Cabanillas Sánchez, Antonio, Las obligaciones de actividad y de resultado (Barcelona, Bosch, 1993), pp. 123-124. 
te en la conducta diligente del deudor dirigida a la satisfacción del interés primario del acreedor.

Por otra parte, es interesante analizar si se debe considerar defectuoso el cumplimiento ejecutado por otra persona distinta al deudor en una relación intuitus personae y, por lo tanto, si cabe oponer la exceptio siendo la prestación ejecutada objetivamente idónea.

$\mathrm{Al}$ respecto, el artículo $1158 \mathrm{CCEsp} .{ }^{33}$ permite que el pago pueda realizarlo cualquier persona, tenga interés o no en el cumplimiento de la obligación, pero, a su vez, el artículo 1161 CCEsp. establece limitaciones respecto a las obligaciones de hacer al señalar: "[...] en las obligaciones de hacer el acreedor no podrá ser compelido a recibir la prestación o el servicio de un tercero, cuando la calidady circunstancias de la persona del deudor se hubiesen tenido en cuenta al establecer la obligación".

Sobre este punto, Díez-Picazo nos señala lo siguiente: "Es notorio que si la persona del deudor y sus especiales cualidades han sido tenidas en cuenta a la hora de configurar la prestación, como condición esencial de ésta (intuitus personae), cualquier pretensión de ejecución de la prestación por un tercero hace que ésta represente un aliud y no sea ya la misma prestación, por lo cual el acreedor podrá justamente rechazarla" ${ }^{34}$. En efecto, el cumplimiento por un tercero distinta a la persona del deudor en obligaciones intuitus personae no constituye un verdadero cumplimiento, debiéndose entender que la prestación no reúne los requisitos para entender extinguida la obligación ${ }^{35}$.

Por tanto, no estamos ante un cumplimiento defectuoso, sino más bien ante un incumplimiento puramente tal, ya que el acreedor al momento de contratar ha tenido en cuenta la persona del deudor y sus especiales cualidades.

En este orden de cosas, el excipens deberá ejercitar la excepción de contrato no cumplido y no de cumplimiento defectuoso, pues no se trata de un cumplimiento que se aleje en parte de lo estipulado, sino que la prestación del tercero no satisface en nada al acreedor, teniendo en cuenta la naturaleza del contrato celebrado ${ }^{36}$.

${ }^{33} \mathrm{El}$ artículo 1158 precisa que "Puede hacer el pago cualquier persona, tenga o no interés en el cumplimiento de la obligación, ya lo conozca y lo apruebe, o ya lo ignore el deudor. El que pagare por cuenta de otro podrá reclamar del deudor lo que hubiese pagado, a no haberlo hecho contra su expresa voluntad. En este caso sólo podrá repetir del deudor aquello en que le hubiera sido útil el pago".

${ }^{34}$ Díez-Picazo, Luis, cit. (n. 2), p. 481

${ }^{35}$ Lacruz Berdejo, José Luis, Elementos de Derecho civil (Madrid, Dykinson, 1999), II, p.133 n. 1, señala: "No cabe, sin embargo, el cumplimiento a través de representante cuando la prestación tenga carácter personalísimo y hayan sido tenidas en cuenta las cualidades y circunstancias personales del deudor al establecer la obligación".

${ }^{36}$ Como indica Albaladejo, Manuel, Derecho civil (Barcelona, Bosch, 2002), p. 


\section{Aplicación de la "exceptio" en obligaciones de medios o actividad.}

La caracterización de una obligación como de medios, afecta a las obligaciones de hacer y supone que el deudor no se obliga al logro de un concreto resultado, sino al despliegue o desarrollo de una actividad o conducta diligente ${ }^{37}$. Es decir, se obliga a poner los medios para la consecución del fin esperado y la aplicación de sus conocimientos específicos.

La propia naturaleza de este tipo de obligación dificulta el análisis de la existencia o no de un cumplimiento inadecuado, pues al no exigirse un resultado concreto no se puede analizar de forma objetiva el supuesto defecto en el cumplimiento. Por consecuencia, el cumplimiento e incumplimiento de la obligación son independientes de la obtención del resultado esperado por el acreedor, y dependen únicamente de la actuación diligente o negligente del deudor ${ }^{38}$.

143, "El fundamento de que pueda pagar cualquier tercera persona ajena a la obligación, tenga o no interés en el cumplimiento de esta (C.C., art. $1158,1^{\circ}$ ) reside en que tendiendo la prestación a satisfacer un interés del acreedor, a éste no debe importarle en principio, quien la realice, con tal de que aquél quede satisfecho". En el caso de las obligaciones instuitus personae, si la prestación no es cumplida con la persona que se ha tenido en cuenta al momento de contratar, el interés del acreedor no queda satisfecho, porque como sabemos se ha contratado a una persona con el fin de que esta misma realice la prestación, por ende no se cumple lo indicado por el autor para que la obligación se entienda extinguida.

${ }^{37}$ Asua González, Clara, Responsabilidad civil médica, en Reglero Campos, Luis Fernando (coordinador), Tratado de responsabilidad civil (Navarra, Aranzadi, 2006), p. 1180. Lовато Gómez, Jesús Miguel, Contribución al estudio de la distinción entre obligaciones de medios y las obligaciones de resultado, en Anuario de Derecho Civil (1992), pp. 653, explica este tipo de obligación de la siguiente manera: "[...] se entiende por obligación de medios aquella obligación en la cual la prestación debida consiste en el despliegue de una actividad del deudor dirigida a proporcionar, de forma mediata, la satisfacción del interés del acreedor, o lo que es lo mismo, en el desarrollo de una conducta diligente encaminada a conseguir el resultado previsto por el acreedor al contratar. Esto es, el deudor debe poner los medios (de ahí el nombre que se le da comúnmente), a través de una actuación diligente, que posibiliten al acreedor obtener el resultado o fin práctico esperado al contraer la obligación, resultado que, sin embargo, no forma parte de la prestación, no está in obligatione. Consiguientemente, su cumplimiento e incumplimiento son independiente de la obtención del resultado esperado por el acreedor y dependen únicamente de la actuación diligente o negligente del deudor".

${ }^{38}$ YzQuierdo Tolsada, Mariano, La responsabilidad civil del profesional liberal (Madrid, Reus, 1989), p. 267, señala, al referirse a la utilidad de la distinción de obligaciones de medio y resultado, lo siguiente: "Admitido que el interés final está siempre presente, en las obligaciones de actividad ese interés es contingente, eventual. El deudor cumple en su programa de prestación observando el esfuerzo o actividad debidos. Con ello se agota un interés primario; y el interés definitivo o final, que es hacia lo que está orientado el comportamiento del deudor, al ser incierto, hace que el deudor quede li- 
En las obligaciones de medios o de actividad, propio en las prestaciones de servicios de profesionales como de médicos y abogados, el canon de diligencia al que deberá atenerse el profesional es al establecido en el artículo 1104, 1 CCEsp. ${ }^{39}$. Si bien este artículo señala como modelo abstracto de conducta al buen padre de familia, para efectos de actividades profesionales como la del abogado, arquitecto o médico, el parámetro de diligencia no puede ser simplemente éste ${ }^{40}$.

De la naturaleza de esta obligación deviene, en este aspecto, un criterio en virtud del cual se determina el modelo de conducta exigible para la satisfacción del interés crediticio concreto. Es decir, de la naturaleza de la obligación se infiere la imposición del modelo de conducta del profesional ${ }^{41}$.

Ahora bien, para poder determinar si existe un incumplimiento es necesario analizar si el deudor se alejó o no, en su conducta, de la diligencia que le exigía el cumplimiento de su prestación. En este sentido, la determinación de un cumplimiento defectuoso pasa por determinar si ha existido o no por el deudor algún grado de actividad destinado al cumplimiento de la obligación.

De esta forma, si el deudor nada ha hecho, olvidando del todo la prestación que debía ejecutar, es manifiesto que estamos frente a un incumplimiento de la obligación, pues al no existir prestación, no hace falta analizar si ésta se realizó de forma diligente o no, en función de la naturaleza de la obligación.

Por el contrario, si ha existido actividad por parte del deudor y por ende se ha realizado la prestación encargada, deberá comprobarse si ésta se realizó según la diligencia que se le exigía en su cumplimiento, y sólo de esta forma podremos distinguir si realmente estamos frente a un cumplimiento defectuoso.

berado si se desplegó esa buena conducta. Se da, pues, un doble juego de intereses en el objeto de la obligación: un interés final aleatorio, al que se aspira, y un interés primario, que se satisface con la actuación profesional diligente, y que en definitiva constituye el auténtico objeto del deber (la prestación de las obligaciones de medio). En este mismo sentido Jordano Fraga, Francisco, Obligaciones de medios y resultados, en Anuario de Derecho Civil (1991), p. 21.

${ }^{39}$ Este artículo señala: "La culpa o negligencia del deudor consiste en la omisión de aquella diligencia que exija la naturaleza de la obligación y corresponda a las circunstancias de las personas, del tiempo y del lugar. Cuando la obligación no exprese la diligencia que ha de prestarse en su cumplimiento, se exigirá la que correspondería a un buen padre de familia".

${ }^{40}$ En cuanto al tipo de conducta que debe seguirse cuando se hace referencia a un buen padre de familia, DíEz-Picazo, Luis, cit. (n. 2), p. 97, señala: "En síntesis, y siguiendo la idea del autor antes citado (Badosa), se trata de un modelo de conducta caracterizado por la no profesionalidad y por una cierta dosis de perfección en el comportamiento".

${ }^{41}$ Serra Rodríguez, Adela, La responsabilidad civil del abogado (Navarra, Aranzadi, 2000), p. 101. 
En este sentido, la determinación de la existencia del cumplimiento defectuoso pasará por conocer el nivel de diligencia empleado por el deudor, y si se comprueba que no ha empleado el exigido por la naturaleza de la obligación, se podrá decir que su cumplimiento es defectuoso.

Por lo tanto, en caso de que exista pleno incumplimiento, en el sentido de no haberse realizado prestación alguna destinada al cumplimiento de la obligación, la exceptio que se debería ejercitar es la non adimpleti contractus. En cambio, si se ha ejecutado la prestación, pero ésta es defectuosa por no ajustarse a la diligencia exigida, la excepción que deberá oponerse es la non rite adimpleti contractus.

No obstante lo señalado, se suele entender que por el sólo hecho de alejarse de la diligencia exigida en el cumplimiento de la prestación, se estaría frente a un incumplimiento, sin distinguir qué tipo de incumplimiento es ${ }^{42}$.

Así, Díez-Picazo señala: "[...] por lo que se refiere a las llamadas obligaciones de medios, en ocasiones conocidas también como obligaciones de diligencia, el panorama varía. Es cierto que en ellas tiene que haberse producido una inobservancia de la regla de diligencia del tipo que ésta sea (diligencia ordinaria, diligencia profesional). Sin embargo, en estos casos la violación de la regla de diligencias o de la lex artis, como también se le llama en relación con la diligencia profesional, no es en puridad un criterio de imputación de responsabilidad, sino un hecho determinante del incumplimiento en sí mismo. La culpa juega evidentemente en este tipo de obligaciones, pero juega porque culpa es igual a incumplimiento" ${ }^{43}$.

En definitiva, el cumplimiento defectuoso está circunscrito en las obligaciones de medios a la falta de diligencia y, por el contrario, la existencia

${ }^{42}$ Para Jordano Fraga, Francisco, cit. (n. 38), p. 24: "Es no cumplimiento para cada obligación, según el artículo 1.101 del C.C. cualquier modo de contravención de su tenor: es decir, todo lo que no sea exacta realización de la prestación debida, tal y como ésta se haya definido para esta determinada obligación".

${ }^{43}$ Díez-Picazo, Luis, cit. (n. 2), p. 586-587. En este mismo sentido Lobato GóMEZ, Jesús Miguel, cit. (n. 37), pp. 718 ss. Serra Rodríguez, Adela, cit. (n. 41), pp. 114 ss., realiza la distinción al diferenciar los conceptos de pericia y de diligencia. En este sentido señala que: "La más importante estriba en que la deficiencia total de pericia comporta la imposibilidad de realizar el objeto del contrato, esto es, el incumplimiento absoluto, mientras que la falta de diligencia, aunque sea total, no conduce a las mismas consecuencias, sino que implica un (in)cumplimiento imperfecto, y por tanto, una prestación posible en virtud de la presencia de la pericia”. JORDANO FRAGA, Francisco, cit. (n. 38), p. 24 ss., distingue de la ausencia de cumplimiento de la falta de exacto cumplimiento. En este sentido señala: "En las obligaciones de medios, como en cualquiera otras, el deudor puede infringir su obligación, no realizando la prestación debida en absoluto (falta total de cumplimiento); no realizándola en parte -p.ej., del total de horas o jornadas de trabajo comprometidas, sólo se realizan por el prestador de facere una porción: cfr. art. 1.151-2 -(falta parcial de cumplimiento) [...]" 
de diligencia independientemente del resultado obtenido conlleva un cumplimiento exacto de la obligación.

Por lo general, el cumplimiento defectuoso en este tipo de obligaciones está acompañado por la existencia de un daño y es gracias a la existencia de este daño que se puede apreciar de mejor manera el cumplimiento defectuoso. En este sentido, la conducta negligente de un médico puede tener nefastas consecuencias en un paciente; lo mismo sucede con un arquitecto en la ejecución de una obra o un abogado en el ejercicio de su profesión. La cuestión pasa por determinar la relación de causalidad entre el actuar del profesional (el cumplimiento defectuoso) y la existencia del daño.

Si bien el daño es una ayuda a la hora de apreciar el cumplimiento defectuoso, éste no es requisito para la acreditación del mismo, toda vez que es posible que en una obligación de medios o de actividad exista un cumplimiento defectuoso sin la existencia de un perjuicio. Ello, pues lo que determina el cumplimiento imperfecto en este tipo de obligaciones es la falta de diligencia en la ejecución, más allá de la existencia posterior de un daño.

Ahora, es lógico que en materia de responsabilidad para exigir una indemnización sea requisito indispensable la acreditación del correspondiente daño, pero en materia del cumplimiento de las obligaciones, al excipens le bastará para poder ejercitar la exceptio non rite adimpleti contractus, acreditar la falta de diligencia en la ejecución de la prestación y que además el resultado esperado no se haya concretado.

Sobre el excipens recaerá la carga de la prueba, debiendo acreditar la defectuosidad o inexactitud de la prestación realizada; es decir, la no conformidad de la prestación a los cánones de conducta que deben regir en el desarrollo de la actividad.

Como señala Jordano Fraga “[...] deberá probar el incumplimiento material de la obligación: la no prestación en absoluto de la conducta diligente debida, la realización atrasada de la conducta diligente debida, o la no exacta realización de la conducta diligente debida: o sea, que la conducta de cumplimiento del deudor, no alcanzó el nivel de diligencia debido, según la obligación. Esto último, es la culpa o negligencia del deudor (en la actividad de cumplimiento), como inexacto cumplimiento obligación de medios, como forma de incumplimiento material de tal obligación, y contenido, por tanto, de la carga probatoria del acreedor" ${ }^{44}$.

En este sentido, la carga probatoria no sufrirá ningún cambio para el excipens, puesto que en materia de cumplimiento inadecuado sabemos que la

${ }^{44}$ Jordano Fraga, F., cit. (n. 38), p. 77. 
carga de la prueba recae siempre sobre éste, al tener que acreditar en qué consiste la defectuosidad que adolece la prestación realizada por el demandante ${ }^{45}$.

\section{Presupuestos para la correcta aplicación DE LA "EXCEPTIO NON RITE ADIMPLETI CONTRACTUS"}

Además de los requisitos de la excepción de contrato no cumplido, que son comunes para ambas excepciones ${ }^{46}$, la exceptio non rite adimpleti contractus debe cumplir con ciertas exigencias concretas para su correcta aplicación.

1. Que el incumplimiento parcial o cumplimiento defectuoso sea de cierta importancia o trascendencia en relación con la finalidad perseguida.

La jurisprudencia del Tribunal Supremo español, dentro de las cuales destacan, entre otras, las sentencias de 13 de mayo de $1985^{47}$, 14 de julio de $2003^{48}$ y 22 de julio de $2008^{49}$, se refieren a este presupuesto señalando: "[...] $e l$ éxito de tal excepción de contrato no cumplido adecuadamente está condicionado a que el defecto o defectos de la obra sea de cierta importancia o trascendencia en relación con la finalidad perseguida y con la facilidad o dificultad de subsanación, haciéndola impropia para satisfacer el interés del comitente, es claro que no puede ser alegado cuando lo mal realizado u omitido carezca de suficiente entidad en relación a lo bien ejecutado y el interés del comitente quede satisfecho con la obra entregada u ofrecida, de forma que las exigencias de la buena fe y el principio de conservación de los contratos, no autoricen el ejercicio de la acción resolutoria del artículo 1.124 del citado texto sustantivo y sólo permita la vía reparatoria, bien mediante la realización de las operaciones correctoras precisas, bien a través de la consiguiente reducción del precio".

Interesante es, a su vez, analizar la última sentencia ya citada, al conocer sobre recurso de casación, que tiene por fundamento la infracción de las normas aplicables para resolver las cuestiones objeto del proceso, basado en la infracción de doctrina del Tribunal Supremo en cuanto a la exceptio non rite adimpleti contractus, en relación con el artículo 1124 CCEsp.

${ }^{45}$ Corresponde al demandado acreditar los hechos que sirvan para desvirtuar o neutralizar la demanda. Es decir, en materia de cumplimiento defectuoso, deberá el excipens acreditar los hechos obstativos que impiden el éxito de la demanda. Siendo estos hechos obstativos la falta de diligencia del actor en la ejecución de su prestación.

${ }^{46}$ Los requisitos comunes que se exigen para el ejercicio de la exceptio en su ambas modalidades son: $i$ ) obligaciones recíprocas o sinalagmáticas; ii) obligaciones de cumplimiento simultáneo; iii) incumplimiento de las obligaciones; y iv) alegación no contraria a la buena fe.

${ }^{47} \mathrm{RJ} 1985 \backslash 2388$

${ }^{48} \mathrm{RJ} 2003 \backslash 4635$

${ }^{49} \mathrm{RJ} 2008 \backslash 4617$ 
En efecto, el recurso se fundamenta en el incumplimiento por parte del demandante reconvencional, del cumplimiento del contrato de arrendamiento de obra, en el sentido de que la maquinaria entregada adolece de vicios o defectos, habiendo abonado el recurrente la mayor parte del precio pactado y rehusado únicamente el pago del resto, aproximadamente una quinta parte del precio.

El Tribunal Supremo, examinando el recurso de casación, y partiendo de la citada valoración probatoria y la conclusión fáctica de que los defectos observados en la máquina no son impeditivos del fin a que se destina; obligando a efectuar los oportunos ajustes para su rendimiento óptimo, y que tales defectos de ajustes no tienen la trascendencia de un incumplimiento contractual, sino que son los propios de su puesta a punto, y sí imponen la obligación de su corrección por el constructor.

Por lo tanto, el Tribunal desestima el recurso de casación, ya que entiende que el cumplimiento defectuoso no tiene la importancia o trascendencia en relación con la finalidad perseguida que amerite el ejercicio de la exceptio non rite adimpleti contractus y, por ende, el efecto que ésta conlleva de detener el cumplimiento de lo reclamado por el demandante reconvencional. De lo contrario, se vulneraría los principios de buena fe y de conservación de los contratos, debiéndose sólo permitir la vía reparatoria, bien mediante la realización de las operaciones correctoras precisas como se ha acordado en la sentencia impugnada, o bien mediante la consiguiente reducción del precio. En definitiva, en el supuesto de autos, se está ante defectos no impeditivos y subsanables mediante los oportunos ajustes, propios de una puesta a punto, habiéndose acordado la realización de ajustes, esto es, la reparación in natura.

En consideración a lo anterior, el Tribunal no accedió a la rebaja del precio, que se suele entender como un "cumplimiento por equivalencia", entendiendo, además, que la exceptio non rite adimpleti contractus sólo habilita a exigir la reparación de lo deficiente o a realizar lo que falte, o a verse indemnizado en una prestación equivalente si no es posible su realización exacta (sentencia del Tribunal Supremo, de 5 de noviembre de 2007 [RJ 2007, 8646]).

Debemos destacar, a nuestro juicio, que el Tribunal no considera la falta de puesta a punto de la maquinaria como un incumplimiento contractual, cuestión básica para ejercitar la exceptio, sin incumplimiento no se puede excepcionar la contraparte con el no cumplimiento de su propia prestación. Todo esto, valorándolo en relación con la finalidad perseguida por las partes, que a juicio del Tribunal se ve cumplida.

De esta sentencia citada, reiterada por la jurisprudencia de los tribunales españoles, se puede, además de desprender los requisitos de la exceptio non 
rite adimpleti contractus, deducir que existen dos principios fundamentales que justifican la aplicación del instituto en estudio ${ }^{50}$.

En caso de que el cumplimiento parcial o defectuoso no revista de una gravedad suficiente, o cuando a pesar de éste, el interés de la contraparte quede satisfecho, el demandado, en vez de ejercer la exceptio non rite adimpleti contractus, tendrá la opción de ejercitar otras acciones que el derecho pone a su alcance, como la posibilidad de solicitar que la irregularidad se subsane in natura o que se reduzca su obligación en la cuantía que requiera la imperfección.

Ahora bien, en caso de que sí se cumpla con los requisitos para el ejercicio de la excepción de contrato no cumplido adecuadamente, esto no impide que el demandado pueda, además, por medio del ejercicio de la correspondiente acción de cumplimiento, solicitar la reparación in natura o la reducción del precio en relación a la imperfección ${ }^{51}$. Son, de esta manera, dos situaciones distintas: la exceptio persigue paralizar el cumplimiento que se le exige por el demandante, hasta que este no cumpla con su obligación en los términos y condiciones pactadas mientras que la acción de cumplimiento busca obtener el fiel cumplimiento de las prestaciones establecidas en el contrato ${ }^{52}$.

${ }^{50}$ Larenz, Karl, Derecho de obligaciones (versión española y notas de Jaime Santos Briz, Madrid, Revista de Derecho Privado, 1958), I, p. 272, señala: "La excepción del art. 320 está también justificada en principio cuando la otra parte no haya cumplido su prestación completamente o lo haya hecho de en forma defectuosa. Sin embargo, aquélla no prosperará cuando el rehusar la prestación infringiría la buena fe según las circunstancias, especialmente en virtud de que la parte incumplida del contrato es insignificante en relación con el todo".

${ }^{51}$ Creemos importante, en este punto, hacer referencia a lo establecido en los Principios de Derecho Europeo de los Contratos que, en su artículo 9:401, establece el derecho de reducir el precio cuando existe un cumplimiento no conforme con lo estipulado. Los PECL. lo sitúan entre los remedios y le dedican una sección independiente, con un único artículo, el 9.401, según el cual $i$ ) la parte que acepta una oferta de cumplimiento no conforme al contrato puede reducir el precio. La reducción proporcional a la disminución de valor de la prestación al tiempo en que la misma era ofrecida, en relación con el valor que hubiese tenido en ese momento una oferta de ejecución conforme; ii) la parte con derecho a reducir el precio conforme al párrafo anterior y que ha pagado ya una suma que excede el precio reducido puede recuperar de la otra parte el exceso; y iii) la parte que reduce el precio no puede obtener también indemnización de daños por reducción en el valor de la prestación, pero conserva el derecho a pedir indemnización por cualquier otro daño que haya sufrido, siempre que éstos sean indemnizables en virtud de la Sección 5 del presente capitulo.

${ }^{52}$ Albaladejo, M., cit. (n. 36), p. 104, señala en este sentido: "Esta excepción (exceptio non rite adimpleti contractus) no impide el que ejercite la acción para pedir que la irregularidad se subsane in natura, o que se reduzca su obligación en la cuantía que requiera la imperfección. Si lo que ocurre es que lo imperfecto del cumplimiento no afecta a que deba apreciarse que globalmente lo hubo, quien lo recibió defectuoso 
Sin embargo, como analizaremos más adelante, es de entender que para el éxito de la exceptio, ésta, la mayoría de las veces, se tendrá que ejercitar en conjunto con la acción de cumplimiento.

\section{El cumplimiento defectuoso debe ser imputable.}

Otro de los presupuestos necesarios que debe reunir la exceptio non rite adimpleti contractus, es el de la imputabilidad del cumplimiento. Para poder poner en ejercicio la excepción de contrato no cumplido adecuadamente, debe ser necesario que dicha no adecuación a los términos establecidos en el contrato se deba a la conducta del demandante, es decir, le debe ser imputable. En caso contrario, éste se podría excusar alegando que no le cabe responsabilidad en aquella parte del cumplimiento que no se ajusta a las condiciones establecidas en el contrato.

En efecto, puede suceder que aquella parte de la prestación que no se ajusta a lo pactado sea consecuencia de un hecho ajeno al obligado, del cual no deba responder, y sea la consecuencia directa del cumplimiento inadecuado. Por lo tanto, es necesario que concurra un requisito especial en relación al cumplimiento defectuoso, que es la imputabilidad en aquella parte de la prestación que no se ajusta a las condiciones establecidas en el contrato.

En la observancia de las prestaciones establecidas en una relación obligatoria pueden intervenir diversos factores, que pueden alterar el normal comportamiento de una de las partes que debe cumplir con las condiciones establecidas en el contrato, y que logren afectar la correcta ejecución de su prestación.

Estos factores o elementos pueden deberse tanto a la culpa, como a la negligencia del deudor al cumplir la prestación, e inclusive al dolo de sus propios actos. En tal supuesto de cumplimiento defectuoso, deberá responder de aquella parte de la obligación que no se ajusta a lo establecido en el contrato $^{53}$. Pero también se puede deber a hechos ajenos a la conducta del obligado, como la concurrencia de un caso fortuito o fuerza mayor, el hecho

no puede utilizar la exceptio non rite adimpleti contractus para no cumplir él nada, sino que sólo puede pedir que antes de hacerlo, se perfeccione el cumplimiento o se reduzca la cuantía de su prestación en valor de la imperfección, o no cumplir él enteramente, sino sólo en la proporción en que el cumplimiento del otro es completo o correcto".

${ }^{53}$ Como regla general el deudor deberá responder cuando el incumplimiento se deba a su culpa, pero además, excepcionalmente, en algunas otras hipótesis en que a pesar de no ser culpable de él, así lo determine la ley o la propia obligación. En este sentido Albaladejo, M., cit. (n. 36), p. 172. 
de un tercero ${ }^{54}$, o la propia culpa de la persona que debía recibir la prestación de la contraparte ${ }^{55}$.

Igualmente el cumplimiento defectuoso puede deberse a la concurrencia de la culpa de la víctima, pero que no corresponda enteramente a su responsabilidad. En este caso, el deudor tendrá que cargar con las consecuencias de su acción que han llevado a cumplir defectuosamente la prestación; es decir, él será responsable en la medida de su contribución causal. El juez deberá atenuar su responsabilidad teniendo en cuenta la real incidencia de su conducta en la producción del daño ${ }^{56}$.

${ }^{54}$ El Código Civil español trata la inimputabilidad en su artículo 1105 , señalando: "Fuera de los casos expresamente mencionados en la ley, y de los en que asílo declare la obligación, nadie responderá de aquellos sucesos que no hubieran podido preverse, o que, previstos, fueran inevitables". Por su parte, el Proyecto de "Principios de derecho europeo de la responsabilidad civil”, distingue entre causas de justificación (art. 7:101) y causas de exoneración de responsabilidad (art. 7:102), según se trate de una responsabilidad por culpa u objetiva. Dentro de las causas de exoneración el proyecto señala la fuerza mayor, conducta de un tercero (art. 7:102) y la culpa de la víctima (art. 8:101). Como señala De Cuevillas Matozzi, Ignacio, La relación de causalidad en la órbita de Derecho de daños (Valencia, Tirant lo Blanch, 2000), p. 186: “[...] se debe tener en cuenta que no cualquier hecho de un tercero es idóneo para desvirtuar el nexo de causalidad que presumiblemente existe entre la conducta del demandado y el daño: debe tratarse de un tercero extraño, por quien no se deba responder. De allí, quedan al margen de esta categoría hechos realizados por terceros por los cuales se debe responder indirectamente, es decir, los que engendran responsabilidad refleja, tales como los dependientes, hijos, aprendices, etc." En esta misma línea, se refiere YzQuierdo Tolsada, M., cit. (n. 38), p. 252, “[...] no se comprende en esta categoría de terceros a aquellas personas que por ley revierten la responsabilidad por sus actuaciones sobre aquella en la que recae la imputación que se examina. Si los Códigos civiles revierten sobre los padres las consecuencias jurídicas de los daños ocasionados por sus hijos menores, o sobre los empresarios las que generan las conductas de sus dependientes, es porque se considera el hecho como suyo propio".

${ }^{55}$ El artículo 9:504 de los Principios de Derecho Europeo de los Contratos reglamenta las pérdidas imputables a la parte perjudicada, señalando: "Cuando el perjudicado hubiera contribuido al incumplimiento o a sus efectos, la parte que incumple no responde de las pérdidas sufridas por la parte perjudicada en lo que es consecuencia de dicho comportamiento".

${ }^{56}$ De Cuevillas Matozzi, I., cit. (n. 54), pp. 186-187; Reglero Campos, Luis Fernando, El nexo causal. Las causas de exoneración de responsabilidad: culpa de la victima y fuerza mayor. La concurrencia de culpas, en REgLERO CAMPOS, Luis Fernando (coordinador), Tratado de responsabilidad civil (Navarra, Aranzadi, 2006), p. 442, expresa: "La intervención de la víctima en el hecho dañoso constituye una circunstancia relativamente frecuente. Cuando esta intervención constituye un aporte causal decisivo y, además, la operación de imputación subjetiva da como resultado un exclusivo juicio de reproche, se considera que el daño debe ser soportado exclusivamente por ella y/o por las demás personas que puedan resultar perjudicadas por el hecho dañoso. Es- 
En todas las situaciones en que no existan casos de concurrencia, se suele destruir por completo el nexo causal que debe unir el daño que proviene del incumplimiento con el actuar del deudor, operando las causas de exoneración de responsabilidad ${ }^{57}$. Por lo tanto, no debería prosperar la exceptio non rite adimpleti contractus cuando el cumplimiento defectuoso no se deba a la conducta imputable del demandante, porque si bien existe un cumplimiento defectuoso, no se puede entender que le sea imputable al deudor.

Por otra parte, desde un cierto punto de vista la imposibilidad sobrevenida transitoria puede ser considerada como un evento de falta de imputabilidad ${ }^{58}$. En este sentido, si el deudor se enfrenta a un evento transitorio que no es debido a su culpa, que ha acontecido con posterioridad al surgimiento de la obligación y que le impida la correcta ejecución de su prestación, llevándole, por ende, a un cumplimiento defectuoso, es lógico que deba denegarse la exceptio non rite adimpleti contractus que se ejercita contra él. Esto es tal, pues cuando el deficiente cumplimiento de su prestación no se debe a su responsabilidad, debe quedar exonerado si el cumplimiento defectuoso no frustra el interés del acreedor.

Ahora bien, en el caso que la obligación tenga un término esencial, o en aquellos casos en que, sin tener tal carácter el término, el transcurso del tiempo provoque que la obligación no satisfaga el interés o la utilidad del acreedor, esta situación se equipararía a la imposibilidad sobrevenida definitiva. Lo anterior, dado que el interés del acreedor se vería frustrado, siendo indiferente para él el cumplimiento o no de la prestación por parte del deudor ${ }^{59}$.

taríamos entonces ante la figura de la culpa exclusiva de la víctima, estudiada en el apartado anterior. Pero cuando tanto la imputación objetiva como la subjetiva se "reparte" entre la víctima y el demandado, procederse entonces a distribuir la carga del daño entre una y otra”. En esta misma línea, Rodríguez Marín, Concepción, Culpa de la victima y responsabilidad sin culpa, en Revista de Derecho Privado, 76 (1992) 1, p. 121.

${ }^{57} \mathrm{La}$ interrupción del nexo causal implica que entre el hecho y el daño actúa una "causa extraña" que interfiere la relación causal. En otras palabras, el daño no puede ser atribuido al deudor, porque él (el daño) no proviene causalmente de su acción, sino que de otro hecho. En el fondo, la interrupción del nexo causal implica reconocer que no ha sido el hecho del deudor el que provocó el perjuicio, quedando, por lo mismo, este último exonerado de responsabilidad. En este sentido, Rodríguez Grez, Pablo, Responsabilidad contractual (Santiago, Editorial Jurídica de Chile, 2003), p. 282.

${ }^{58}$ El Código Civil español se refiere al concepto de imposibilidad sobrevenida para aplicarlos a las obligaciones de hacer en su artículo 1184 .

${ }^{59}$ Bustos Valdivia, Inmaculada, La suspensión del pago del precio en la compraventa (Valencia, Tirant lo Blanch, 1999), p. 196, señala: "Recapitulando, de lo expuesto resulta, en primer lugar, que cabe hablar de dos tipos de imposibilidades transitorias, una primera en la cual el impedimento no frustra el interés del acreedor y otra en la que sí. En cada uno de esos casos la imposibilidad tendrá unos efectos distintos, en la 
Se deberá seguir esta misma línea en el evento que la imposibilidad sobrevenida no permita llevar a cabo el cumplimiento de la obligación. En este supuesto, la imposibilidad actúa como un modo de extinción de las obligaciones $^{60}$. Al no poder seguir adelante con la ejecución del contrato, carece de sentido el ejercicio de la exceptio, por lo cual el demandado de cumplimiento deberá, en esta situación, reconvenir solicitando la resolución del contrato.

Cabe destacar en este punto que no es necesario la existencia del daño para ejercitar la exceptio non rite adimpleti contractus, bastando la sola existencia de un cumplimiento inadecuado, es decir, que la prestación del deudor no se ajuste a las condiciones establecidas en el contrato. El daño es un elemento necesario que se exige para hacer valer la responsabilidad y su correspondiente indemnización de perjuicios, cuestión que no necesariamente se persigue en materia de excepción de contrato no cumplido adecuadamente, que como sabemos, tiene como fin enervar el pago de la contraprestación hasta que los defectos de la prestación hayan sido corregidos.

\section{El cumplimiento defectuoso no debe ser de fácil subsanación.}

La dificultad de subsanación es otro de los requisitos que la jurisprudencia española tiene en cuenta al momento de ponderar la admisibilidad de la excepción de incumplimiento defectuoso, pues si lo mal realizado es fácilmente subsanable por el excipens, no se justifica oponer la exceptio non adimpleti contractus. No es defendible detener el cumplimiento del contrato por una cuestión que no incida en la economía de éste o no tenga un real significado en el contenido de la prestación.

Además, si es fácil de subsanar el defecto de la prestación, se estaría ejercitando el instituto en contra del principio de buena fe que debe imperar en toda relación contractual.

Dentro de la jurisprudencia, que establece como presupuesto la dificultad de subsanación, se encuentra, entre otras, la sentencia del Tribunal Supremo de 22 de julio de 2008, que declara: "El incumplimiento parcial exige valorar más pormenorizadamente en la instancia su entidad y repercusión en la economía del contrato, ya que el éxito de tal excepción de contrato no cumplido adecuadamente está condicionado con la finalidad perseguida y con la facilidad o dificultad de su subsanación [.... ${ }^{61}$ “.

segunda en concreto, los efectos serán equiparables a los que posee la imposibilidad definitiva".

${ }^{60}$ Sobre la imposibilidad sobrevenida, véanse: Albaladejo garcia, M., cit. (n. 36); Díez-Picazo, L., cit. (n. 2).

${ }^{61}$ RJ 2008\4617, en este mismo sentido, las sentencias del Tribunal Supremo de 14 de julio de 2003 (RJ 2003\4635), 16 de diciembre de 2005 (RJ 2005\153) y 15 de mayo de 1985 (RJ 1985\2388). 


\section{El cumplimiento defectuoso debe ser de una suficiente entidad en relación} con la parte ejecutada regularmente.

Este presupuesto está en consonancia con el anterior ya expuesto, pues lo que pretende la jurisprudencia con este requisito y el anterior es exigir que el cumplimiento defectuoso tenga ciertas características que hagan plausible el ejercicio de la excepción de cumplimiento defectuoso, y así evitar que se ejercite ante cualquier tipo de incumplimiento menor.

Por consiguiente, el Tribunal, deberá tener en cuenta la entidad del defecto en la prestación ejecutada, en relación a lo bien ejecutado; es decir, que no se trate de un incumplimiento menor, al compararlo con la parte de la prestación que sí se ha ejecutado conforme a lo establecido en el contrato ${ }^{62}$.

De este requisito podemos precisar que la jurisprudencia en un cumplimiento defectuoso exige, al menos, que una parte de la obligación se haya cumplido según los términos del contrato. Sólo de esta forma se puede realizar la comparación en las prestaciones de la misma obligación y concluir así la existencia de la defectuosidad.

Creemos que la cuestión no es tan sencilla, pues es posible que en ciertos cumplimientos defectuosos no existan partes de la obligación que se encuentren bien cumplidas; es decir, que estén ajenas de defectuosidad y, por lo tanto, complejice el análisis comparativo para la determinación de la existencia de un cumplimiento defectuoso o parcial.

Por lo demás, sostenemos necesario apuntar sobre las dudas que pudiera merecer este cuarto presupuesto como tal, pues ya el primer requisito hace referencia sobre la necesidad de que el incumplimiento sea de cierta importancia o trascendencia, con lo cual podría entenderse que ya se exige este requisito para que se configure plenamente la exceptio non rite adimpleti contractus.

La cuestión pasa por determinar si son dos requisitos independientes entre sí, en el sentido de que ambos deben concurrir para llegar a configurar la exceptio en estudio, o, por el contrario, son dos formas distintas de valorar la suficiente entidad que se exige respecto del cumplimiento defectuoso.

En nuestra opinión, son dos requisitos autónomos entre sí, pues si bien la

${ }^{62}$ De esta forma lo entiende la sentencia del Tribunal Supremo de 15 de marzo de 1979 (RJ 1979\871), al señalar: "[...] pues respondiendo aquélla a la finalidad de protección del equilibrio entre las obligaciones reciprocas y al sinalagma funcional o interdependencia que es su caracteristica, no podrá ser alegada la excepción de falta de cumplimiento regular cuando lo mal realizado u omitido en esa prestación parcial o defectuosa carezca de suficiente entidad con relación a lo demás bien ejecutado [...] ". En este mismo sentido, las sentencias del Tribunal Supremo 15 de mayo de 1985 (RJ 1985\2388), 14 de julio de 2003 (RJ 2003\4635), 16 de diciembre de 2005 (RJ 2005\153) y 22 de julio de 2008 (RJ 2008\4617). 
suficiente intensidad o la trascendencia es un elemento que pertenece a ambos requisitos, luego se alejan, al exigirse, en el primero, que la trascendencia o importancia sea en relación a la finalidad perseguida, y en el segundo, que el defecto sea de suficiente entidad en relación a la parte bien ejecutada. En este sentido, no bastará que la trascendencia del defecto no cumpla sólo con la finalidad perseguida, sino que será necesario, además, que tenga la suficiente dimensión en relación con la parte ejecutada regularmente.

Por lo tanto, cuando el cumplimiento de una de las partes no es del todo regular, pero cumple con la finalidad perseguida por ellas, no se podría ejercitar la exceptio por la falta de uno sus presupuestos, aunque el defecto en el cumplimiento tenga la suficiente entidad en relación con la parte ejecutada regularmente. Es decir, deberá siempre, según nuestra opinión, concurrir ambas circunstancias; esto es, que no se cumpla la finalidad perseguida y que la parte mal ejecutada al compararla con la regularmente cumplida sea de suficiente entidad.

\section{Efectos Que persigue el ejercicio de la “exceptio”}

La consecuencia o el efecto que persigue el excipens al ejercitar la exceptio es que el cumplimiento de su prestación se paralice, al entender, el demandado, que su prestación se debe cumplir de forma simultánea a la del demandante ${ }^{63}$.

La sentencia del Tribunal Supremo español de 27 de diciembre de $2012^{64}$, señala: "Debe recordarse que la excepción de incumplimiento contractual, en cualquiera de sus dos modalidades -exceptio non adimpleti contractus y exceptio non rite adimpleti contractus-, supone, simplemente, la negativa totalo parcial al pago de la obligación reclamada y constituye una de las consecuencias más importantes del carácter sinalagmático de un contrato y del principio de reciprocidad de las obligaciones en ella comprendidas, pues se funda en la regla del cumplimiento simultáneo de las prestaciones reciprocas y en la idea de que cada parte pueda rehusar o rechazar el cumplimiento de la obligación prevista a su cargo, mientras la otra parte no cumpla con la suya $y$, a la inversa, en que ninguna de las partes puede demandar el cumplimiento de la obligación contraria, sin cumplir u ofrecer el cumplimiento de la obligación propia. Se

${ }^{63}$ Así lo señala, por ejemplo, Fernández URzaineui, Francisco Javier, La regla de la simultaneidad en el cumplimiento de las obligaciones bilaterales, en Revista Critica Derecho Inmobiliario (1997), p. 424, al señalar: "En principio, de la variante non rite no se derivan consecuencias sustantivas y procesales distintas de las que determina la excepción general. En una y otra la ejecución de la prestación reclamada al demandado queda en suspenso, diferida o condicionada a la total y exacta realización simultánea por parte del actor de la prestación que correlativamente le incumbe".

${ }^{64}$ JUR 2012/42876 
trata de una verdadera excepción, tanto en su sentido sustantivo -porque es un derecho o facultad para rechazar la ejecución de la prestación puesta a cargo de quien la opone-, como en su sentido procesal-porque constituye el justo fundamento de oposición a la demanda de cumplimiento, en los términos en que ésta se encuentra planteada, de modo que es siempre un modo de defensa a favor del demandado-".

Igualmente la sentencia de la Audiencia Provincial de Málaga de 12 de mayo de $2000^{65}$, indica: "[...] en efecto, de la excepción de cumplimiento inadecuado o de contrato no cumplido regularmente no se derivan consecuencias procesales distintas que las que determina el incumplimiento contractual, esto es, que la ejecución de la prestación reclamada al demandado queda en suspenso, condicionada, a la realización simultánea por parte del actor de la prestación que le incumbe. La reciprocidad que ha de presidir el desarrollo de las obligaciones bilaterales y a la equidad que debe inspirar la aplicación de las normas conforme establece el articulo 3.2 del Código Civil, lleva a la adopción de soluciones correctoras, conforme a la jurisprudencia del Tribunal Supremo, con la finalidad de restablecer el equilibrio en las prestaciones, que pasan por la reducción parcial de la prestación reclamada en medida equivalente $o$ proporcional a la parte que al demandante resta por cumplir la suya y asi en la Sentencia de 23 de diciembre de 1993, tras establecer que no habia propio incumplimiento, sino incumplimiento defectuoso de la constructora, declara que la obligación de reparar sin que ello releve al dueño de la obra del cumplimiento a su vez de lo que le incumbe conforme a lo pactado".

Finalmente, la sentencia citada, confirma la sentencia recurrida en el sentido de que condiciona la condena al demandado, a la reparación por el actor de estos defectos de ejecución.

\section{ARTiCULACIÓN DE LA “EXCEPTIO NON RITE ADIMPLETI CONTRACTUS" Y LA ACCIÓN DE CUMPLIMIENTO}

La exceptio non rite ejerce su mayor influencia en la órbita de los contratos de arrendamiento de obra y, en menor medida, en los contratos de compraventa. Esto, debido a que es en estos contratos donde el comitente o comprador sufren con mayor frecuencia un cumplimiento irregular o defectuoso de la prestación que ha recibido. Esto se colige gracias al estudio de la jurisprudencia española, donde se aprecia que la exceptio non rite adimpleti contractus es de frecuente ejercicio en este tipo de contratos.

Ahora bien, es útil diferenciar los distintos supuestos que pueden entrar en juego cuando se ejercita la exceptio, pues sabemos que la excepción de

${ }^{65}$ JUR 2000\264177 
incumplimiento defectuoso constituye la vertiente procesal del derecho a suspender el pago por incumplimiento, pero no conlleva en sí misma otra solicitud que fundamente al Tribunal ordenar el cumplimiento de la prestación, mediante la reparación in natura o a través de la reducción del precio.

En efecto, para el ejercicio de la excepción de cumplimiento defectuoso es indispensable que se demande al comitente o al comprador el cumplimiento de la obligación. Sólo de esta manera el excipens podrá hacer ejercicio de la exceptio.

En cambio, para el ejercicio de la acción de cumplimiento como es obvio no hace falta ser demandado, sino que es necesario que se demande el cumplimiento defectuoso, el cual se podrá motivar en el caso de la compraventa en las normas de saneamiento por vicios ocultos ${ }^{66}$, o en la existencia de un aliud pro alio ${ }^{67}$.

En el caso del contrato de arrendamiento de obra, la acción de cumplimiento se podrá fundar en el incumplimiento del contrato por la existencia defectos en la ejecución del mismo; es decir, en las normas generales de derecho de obligaciones, siendo útil, en este caso, los artículos 1101 y 1124 CCEsp.

Ahora bien, lo normal es que con el ejercicio de la exceptio se demande reconvencionalmente el cumplimiento de la prestación de la contraparte, pues el fin de la exceptio non rite adimpleti contractus es suspender el cumplimiento de la prestación de forma momentánea, hasta que el demandante cumpla con lo suyo, ya que existe la voluntad de seguir adelante con la ejecución del contrato.

Por lo tanto, no sería congruente oponer la exceptio sin demandar a su vez el cumplimiento, ya sea solicitando la reparación in natura o la reducción del precio. Creemos que de no ser así, el Tribunal tendría fundamento de

${ }^{66}$ Las normas que regulan los vicios ocultos en la compraventa, se regulan en los artículos 1484 ss. CCEsp. Básicamente, estas normas protegen al comprador de los defectos ocultos que tuviere la cosa vendida, si la hacen impropia para el uso al que se destina, o si disminuye de tal modo este uso que, de haberlos conocido el comprador, no lo habría adquirido o habría dado menos precio por ella. En efecto, se permite al comprador optar entre desistir del contrato, abonándose los gastos que pagó, o rebajar una cantidad proporcional del precio. Respecto a esta opción se refiere el artículo 1486 CCEsp.

${ }^{67}$ En esencia, la doctrina jurisprudencial del aliud pro alio consiste en la ficción de entender que el vendedor entrega una cosa distinta a la debida, no solo cuando pone en poder y disposición del comprador un bien materialmente distinto al vendido; sino también cuando la cosa que se le entrega es absolutamente inútil para el fin que se destina, por carecer las cualidades previstas en el contrato o presupuestas por las partes al tiempo de su celebración. Así lo expresa De Verda y Beamonte, José Ramón, Saneamiento por vicios ocultos (Valencia, Aranzadi, 2009), p. 313. 
poder rechazar la exceptio, pues si la acepta, las partes quedarían en un estado de incumplimiento, ya que la aceptación de la exceptio non rite adimpleti contractus sin el ejercicio de la demanda reconvencional no puede conducir a liberar al excipens del cumplimiento de sus prestaciones ${ }^{68}$.

En consecuencia, se opondría al fin del instituto, que persigue respetar el cumplimiento simultáneo de las obligaciones recíprocas con dicho carácter. Además, se enfrentaría a las normas de buena fe y al principio de conservación de los contratos, que deben respetarse no sólo en el momento de su celebración, sino durante toda la vida contractual hasta su completa ejecución.

\section{Coordinación de la "exceptio non rite adimpleti contractus" y de la acción de cumplimiento en el contrato de compraventa.}

Sabemos que en materia de compraventa, el demandado podrá ejercitar la exceptio y, a su vez, demandar reconvencionalmente por el cumplimiento defectuoso de la prestación del demandante. Por consiguiente, el excipens tendrá que elegir entre dos caminos que el Derecho le ofrece, es decir, demandar por vía reconvencional la defectuosidad de la prestación, basándose en la existencia de un vicio oculto, o en la existencia de un aliud pro alio.

Uno u otro camino tienen consecuencias distintas, pues en el caso de elegir las acciones edilicias, es decir, la acción redhibitoria y quanti minoris que regula el artículo 1486 CCEsp. ${ }^{69}$, su plazo de caducidad, según el artículo 1490 CCEsp. ${ }^{70}$, es de sólo 6 meses desde que se recibe la cosa, con lo cual, el tiempo de protección es más reducido si lo comparamos con el ejercicio de la acción que se fundamente en la existencia de un aliud pro alio. Esta acción, que se fundamenta en la inhabilidad del objeto, por no reunir las cualidades para el uso a que tenía que ser destinado, tiene un período de protección mucho más amplio. Esto, debido a que la demanda que se fundamenta en la existencia de aliud pro alio, se basa en el incumplimiento contractual, quedando al efecto su ejercicio bajo el plazo de prescripción señalado en el artículo $1.964^{71}$ del C.C.

${ }^{68}$ En este sentido, se pronuncian las sentencias del Tribunal Supremo de 15 de marzo de 1979 (RJ 1979\871), 30 de enero de 1992 (RJ 1992\1518), 8 de junio de 1996 (RJ 1996\4833) y 21 de marzo de 2003 (RJ 2003\2763).

${ }^{69}$ Este artículo indica expresa: "En los casos de los dos artículos anteriores, el comprador podrá optar entre desistir del contrato, abonándosele los gastos que pagó, o rebajar una cantidad proporcional del precio, a juicio de peritos. Si el vendedor conocía los vicios o defectos ocultos de la cosa vendida y no los manifestó al comprador, tendrá éste la misma opción y además se le indemnizará de los daños y perjuicios, si optare por la rescisión".

${ }^{70}$ Esta norma dice: "Las acciones que emanan de lo dispuesto en los cinco artículos precedentes se extinguirán a los seis meses, contados desde la entrega de la cosa vendida".

${ }^{71} \mathrm{El}$ cual señala: "La acción hipotecaria prescribe a los veinte años, $y$ las personales que no tengan señalado término especial de prescripción a los quince". 
Esta distinción, además, resulta importante, pues, según si ejercita las acciones edilicias o la acción de cumplimiento en virtud de la existencia de aliud pro alio, puede ser exitoso o no el resultado de la exceptio. Esto principalmente se debe a que el Tribunal Supremo español aplica la distinción entre vicio y aliud pro alio; con el objeto, entre otras cosas, de impedir el ejercicio de la exceptio non rite adimpleti contractus.

En efecto, en un primer momento, el Tribunal Supremo se mostró favorable a la compatibilidad de las acciones edilicias con las de incumplimiento, permitiendo al comprador la posibilidad de optar por el ejercicio de una $\mathrm{u}$ otras, en el supuesto que el defecto que concurriera en la cosa entregada la hiciera totalmente inútil para el uso a que se le destinaba ${ }^{72}$.

Posteriormente, a partir de la sentencia del Tribunal Supremo de 23 de marzo de $1982^{73}$, la doctrina jurisprudencial ha venido considerando que sólo es posible aplicar las reglas de incumplimiento cuando la cosa entregada merezca el calificativo de aliud pro alio, entendiendo por tal caso en que el defecto provoque la inhabilidad del objeto, al resultar equivalente a un pleno incumplimiento, es decir, que se trate de un defecto grave. Cuando el defecto no merece el calificativo de grave, la jurisprudencia del Tribunal Supremo, como veremos posteriormente, niega la aplicabilidad de las reglas del incumplimiento y, por tanto, ha de continuar sometiéndose a la disciplina edilicia ${ }^{74}$.

Según Bustos Valdivia: “[...] fundar la aplicabilidad de uno u otro estatuto jurídico de la entidad del defecto, aunque razonable desde el punto de vista de la justicia, resulta contrario a toda lógica jurídica. Pero, todavía lo es más que la entidad del defecto determine una calificación jurídica diferente. Si la entrega de una cosa con defectos es o no incumplimiento, lo será en todos los casos. A lo sumo, la gravedad del defecto podría ser determinante, si se estima que es un incumplimiento -como en nuestra opinión, de acuerdo con un buen número de autores- para conceder al comprador el extremo remedio de la resolución del contrato; pero no para poder reconocer al comprador el poder ejercitar otras facultades como es el poder suspender el pago del

${ }^{72}$ De Verda y Beamonte, J. R., cit. (n. 67), p. 317.

${ }^{73} \mathrm{RJ}$ 1982 \1500. Así también las sentencias del Tribunal Supremo de 10 de junio de 1983 (RJ 1983\3454), 22 de octubre de 1984 (RJ 1984\4909), 15 de abril de 1987 (RJ 1987\2710), 7 de enero de 1988 (RJ 1988\117), 26 de octubre de 1990 (RJ $1990 \backslash 8052$ ), 1 de marzo de 1991 (RJ 1991 \1708), 14 de mayo de 1992 (RJ 1992\4121), 7 de abril de 1993 (RJ 1993\2798), 17 de febrero de 1994 (RJ 1994\1621), 28 de febrero de 1997 (RJ 1997\1332), 1 de julio de 2002 (RJ 2002\5512), 9 de marzo de 2005 (RJ 2005\2219), 6 de noviembre de 2006 (RJ 2006\6720) y 9 de julio de 2007 (RJ 2007\5433) entre otras.

${ }^{74}$ Bustos Valdivia, I., cit. (n. 59), p. 77. 
precio. Donde sí sería relevante, la mayor o menor gravedad del defecto es en la determinación de la cuantía suspendida"75.

Por lo tanto, en el caso de que el defecto no constituya suficiente gravedad, las reglas aplicables serán las normas de saneamiento por vicios ocultos, debiendo entrar en juego las acciones edilicias. De esta manera se excluye la posibilidad de ejercitar la exceptio non rite adimpleti contractus, debiéndose aplicar las normas específicas de la acción redhibitoria o la reducción del precio.

Así, por lo demás, lo entiende la jurisprudencia mayoritaria. Por ejemplo, la sentencia del Tribunal Supremo de 5 de noviembre de 1987, en un caso en que los defectos consistían en humedades en el cuarto de baño cuya reparación se valoró en 120.000 pesetas, los consideró de escasa importancia, por lo que no estaba justificado el impago del precio y se resolvió el contrato instado por el vendedor. A respecto sostuvo: “[...] el supuesto de autos no era posible comprenderlo en el articulo 1.502, ello aparte, de que la existencia de los defectos hechos mención por su escasa importancia cualitativa y cuantitativa no permitía generar la hipótesis de haber mediado un incumplimiento contractual de la sociedad vendedora previo al imputado a la contraparte [...]"

En el procedimiento de la sentencia del Tribunal Supremo de 6 de noviembre de $1987^{76}$, se alegó, para justificar el impago del precio, la deficiente calidad de los mármoles, madera y decoración. La Sentencia estimó, debido a que su importe ascendía a 150.000 pesetas, que los defectos eran sin importancia e insuficientes para paralizar la resolución, declarando que el leve incumplimiento del vendedor que entrega la cosa con pequeñas deficiencias no le convierte en incumplidor y menos cuando la compradora nunca había hecho reclamación alguna antes del proceso $^{77}$.

De Verda y Beamonte, reflexiona señalando que "[...] sin embargo, no es menos cierto que la tutela que la referida doctrina jurisprudencial ofrece

${ }^{75}$ Ibíd., p. 77.

${ }^{76} \mathrm{RJ} 1987 \backslash 8342$

${ }^{77}$ En este mismo sentido, la sentencia del Tribunal Supremo de 12 de julio de 1991 (RJ 1992\1547), que textualmente recoge: “[...] para producirse un pronunciamiento absolutorio en virtud de la citada excepción, es requisito indispensable que el demandado pruebe que el montante cuantitativo que, en su caso, signifique el daño originado por el incumplimiento del demandante (vendedor), tenga la suficiente entidad como para determinar, que el otro contratante quede exonerado de su obligación de pago, al ser obvio que cualquier incumplimiento no hace presumible postular tal exoneración, habida cuenta que la conclusión contraria llevaría a la consecuencia inadmisible de introducir un desequilibrio en las prestaciones". Así también, la sentencia del Tribunal Supremo de 22 de octubre de 1987 (RJ 1987\7308) que señala: "[...] los defectos originarios del inmueble vendido suponian una mera ejecución defectuosa, sin entidad suficiente para determinar la suspensión del pago alegado [...]" 
al comprador es incompleta, porque, al menos teóricamente, sólo le protege cuando en la cosa que se le entrega concurren defectos de tal gravedad, que la hacen absolutamente inútil para el uso que se le destina, pero no cuando presenta defectos de menor importancia, que no pueden ser subsumidos en la noción de aliud pro alio, ante los cuales el comprador solamente contará con las acciones edilicias, lo que puede suponer privarle de toda tutela, si, como suele ser frecuente, en el momento de la interposición de la demanda, están ya caducadas" 78 .

En efecto, entendemos que el cumplimiento defectuoso es un tipo de incumplimiento y, que en materia de compraventa, en situaciones de incumplimientos menores no debería estar sólo protegido por las acciones edilicias. Es cierto que no debería dar lugar a la solicitud de la resolución del contrato, pero sí a entender que bajo el amparo de la buena fe se pueda retener la parte del precio proporcional a la cuantía estimada que tenga el defecto de la prestación ejecutada. No resulta lógico que deba entregar la totalidad del precio, cuando con posterioridad se pueda determinar que el demandante deba restituir el precio recibido, con el riesgo que posteriormente el vendedor demandante resulte insolvente. El objetivo que cumpliría aquíla exceptio non rite adimpleti contractus es dejar a salvo al comprador del riesgo de insolvencia del vendedor, en caso de que tenga posterior derecho a recuperar el precio o a reducirlo en función del incumplimiento ${ }^{79}$.

Además, se debe tener presente que la acción redhibitoria tiene un carácter rescisorio, por ende se exige para su ejercicio la existencia de un vicio oculto y grave al tiempo de su celebración ${ }^{80}$. Finalmente, cada vez que el

${ }^{78}$ De Verda y Beamonte, J. R., cit. (n. 67), p. 314.

${ }^{79}$ En este sentido, Bustos Valdivia, I., cit. (n. 59), p. 82.

${ }^{80} \mathrm{Al}$ respecto, es claro SANTOS BRIZ, Jaime, Derecho civil: Teoría y práctica (Madrid, Edersa, 1973), IV, pp. 78-79, al entender que la acción redhibitoria ha de incluirse entre los casos de rescisión que comprende el artículo $1291,5^{\circ}$ CCEsp., precisando el autor que tal acción rescisoria no cabe confundirla con la acción resolutoria del artículo 1124 CCEsp.; González Poveda, Pedro, Comentario al art. 1.486 C.C., en Sierra Gil de la Cuesta, Ignacio (coordinador), Comentario del Código Civil (Barcelona, Bosch, 2006), VII, artículos 1.315-1.542, p. 573, observa que: "Por la acción redhibitoria se faculta al comprador para desistir del contrato; dada su naturaleza rescisoria sus efectos serán los generales de esta clase de acciones, es decir, obliga a la devolución de las cosas que fueron objeto del contrato, con sus frutos, y el precio, con sus intereses". También lo entiende de esta manera De Verda y Beamonte, J. R., cit. (n. 67), pp. 296 ss. Llacer Matacás, María Rosa, El saneamiento por vicios ocultos en el Código civil: su naturaleza jurídica (Barcelona, Bosch, 1992), p. 121, precisa al respecto que: "La acción redhibitoria, como acción rescisoria, permite la impugnación de un contrato perfeccionado y apto para producir efectos. Su destrucción retroactiva permite eliminar la falta de equivalencia (vicio de la causa) y restablece la situación anterior a la perfección del contrato". 
cumplimiento defectuoso no revista de una suficiente entidad, el excipens sólo tendrá al alcance la acción estimatoria o quanti minoris. Esto porque, como señalamos, la acción redhibitoria al igual que el aliud pro alio exige una entidad mayor en el defecto de la prestación en comparación con la acción estimatoria, reduciendo aún más las posibilidades del comprador ante el cumplimiento defectuoso del vendedor.

Por otra parte, se debe tener en cuenta que siempre es posible que entren en juego otro tipo de normativas, como la que protege a los consumidores y usuarios en el Real Decreto $N^{\circ} 1 / 2007$, del 16 de noviembre. En efecto, en el ámbito de aplicación de esta ley, el comprador puede, en virtud de los artículos 119,120 , y 121 solicitar la reparación del producto, sustitución del producto, rebaja del precio y la resolución del contrato. Consiguientemente, el consumidor o usuario en virtud de esta ley que le protege, podrá coordinar el ejercicio de la exceptio non rite adimpleti contractus, solicitando la suspensión del cumplimiento de su prestación y, a su vez, demandar reconvencionalmente cualquiera de las opciones que conforme a derecho le otorgue el Real Decreto $N^{\circ} 1 / 2007$, del 16 de noviembre ${ }^{81}$. En caso de que el comprador pretenda exigir responsabilidades en virtud del incumplimiento contractual, tendrá todas las opciones que ofrece este camino; es decir, exigir la resolución o el cumplimiento a través de la reparación del bien, o la reducción del precio. El abanico de opciones es más amplio, pues tiene a su disposición todo el catálogo que ofrece en esta materia el incumplimiento contractual. Obviamente que para decantarse por esta opción, deberá tratarse como ya lo señalamos, de un incumplimiento grave, asimilable a un aliud pro alio.

No obstante lo señalado, creemos que la solicitud de reparación no debería exigir un incumplimiento de carácter grave, bastando que sea similar al tipo de incumplimiento que la jurisprudencia exige para las acciones edilicias. No tiene lógica jurídica, que ante el incumplimiento del vendedor, y pasado el plazo de 6 meses para ejercer las acciones edilicias, el comprador quede desprotegido ante un incumplimiento menor y no pueda solicitar la reparación del bien que ha adquirido, ya que no está solicitando ni la rebaja del precio ni la resolución del contrato, sino que está pidiendo que la entrega del bien cumpla las características que tenía al momento de ser adquirido.

Este razonamiento está en concordancia con las facultades que otorga el Real Decreto $N^{\circ} 1 / 2007$, pues esta ley, como señalamos, faculta a solicitar la

${ }^{81}$ El artículo 121 de esta ley regula la rebaja del precio y resolución del contrato, señalando: "La rebaja del precio y la resolución del contrato procederán, a elección del consumidor y usuario, cuando éste no pudiera exigir la reparación o la sustitución y en los casos en que éstas no se hubieran llevado a cabo en plazo razonable o sin mayores inconvenientes para el consumidor y usuario. La resolución no procederá cuando la falta de conformidad sea de escasa importancia". 
reparación o sustitución a elección del usuario y consumidor, y sólo en caso que no sea posible esto, le permite la rebaja del precio.

Ahora bien, parte de la doctrina entiende que el ejercicio intempestivo de la exceptio en la órbita del contrato de compraventa, puede dar lugar a un ejercicio que no esté acompañado de la buena fe. Se entiende que en el caso de que exista un cumplimiento defectuoso, el comprador debiera haber hecho ejercicio de las acciones correspondientes, para obtener un cumplimiento conforme al contrato, y no esperar a ser demandado por el vendedor al pago del precio debido y, recién en este momento, ejercer la exceptio junto a las acciones tendientes a lograr el cumplimiento idóneo de la prestación ${ }^{82}$.

En consecuencia, señala Orti Vallejo, el comprador sólo estaría legitimado para oponer la excepción cuando lo que se persiguió al suspender el pago fue compeler al vendedor a que mejore el cumplimiento (repare la falta de conformidad o sustituya la cosa) y, para ello, parece que tendría que comunicar al vendedor la razón de su conducta ${ }^{83}$. Lo que no vale es hacerlo en el proceso. Eso no quiere decir que el comprador que suspende el pago del precio y omita comunicar la razón de ello, no pueda luego hacer valer una vez demandado otros medios de tutela (distintos de la exceptio), como serían las acciones de reparación, sustitución, reducción del precio o resolutoria. Lo que ocurre es que esas actuaciones no las hará valer como excipens, sino como reconvinientes.

Por otra parte, cabe preguntarse en qué situación queda la exceptio non rite adimpleti contractus cuando se demanda reconvencionalmente mediante las acciones edilicias los vicios ocultos de la cosa entregada en la compraventa

${ }^{82}$ En sentido similar: Espin Canovas, Diego, La excepción de incumplimiento contractual, en Anuario de Derecho Civil, 17 (1964), pp. 570; y Persico, Giovanni, L'eccezione d'inadempimento (Milano, Giuffrè, 1955), p. 129. Parte de la jurisprudencia del Tribunal Supremo se encuentra en esta misma; en este sentido; así, por ejemplo, la sentencia del 8 de noviembre de 1982, que señala textualmente: "[...] la existencia de los vicios constructivos de que se nutre la defensa del demandado-recurrente (comprador), acaso podrian haber servido de adecuado apoyo a la reclamación pertinente, pero no pueden traerse a cómputo para justificar la falta de pago de la mayor parte del precio, aplazado en los términos del contrato, máxime no habiéndose alegado los vicios, ni siquiera extrajudicialmente, hasta el momento que, ya tardiamente y por via de respuesta al requerimiento resolutorio [...] no constando en manera alguna acreditados y ni siquiera alegados otras anteriores manifestaciones de la disconformidad del comprador". De esta misma manera, la sentencia del Tribunal Supremo de 5 de noviembre de 1987, señala: “[...] no existió constancia de que el comprador hubiera mostrado su disconformidad con el estado de la vivienda adquirida hasta que en contestación al requerimiento notarial, aludió a las reclamaciones por defectos constructivos [...]" En este mismo sentido, la sentencia del Tribunal Supremo de 6 de noviembre de 1987.

${ }^{83}$ Orti VAllejo, Antonio, Los defectos de la cosa en la compraventa civily mercantil (Granada, Comares, 2002), p. 198. 
y la acción se encuentra ya prescrita por el breve plazo establecido para estas acciones. ¿El cumplimiento simultáneo de las obligaciones recíprocas debe quedar sin protección? En este sentido, ¿la exigencia de que este tipo de obligaciones prescriba a los seis meses conlleva que la exceptio non adimpleti contractus prescriba también en ese lapso de tiempo? ¿Deben estar relacionados el éxito de una excepción que se opone en la contestación de la demanda con las acciones que se ejercita en la demanda reconvencional?

El vendedor, por su parte, puede reclamar el precio del contrato de compraventa más allá del plazo de caducidad de seis meses establecidos para las acciones edilicias, ya que su acción de cumplimiento se encuentra sometida al plazo quincenal que señala el artículo 1964 CCEsp. Por lo tanto, es posible que el vendedor, transcurrido seis meses, proceda a demandar la parte del precio debida por el comprador; quedando éste sin la posibilidad de reclamar a su vez el posible cumplimiento defectuoso del vendedor, salvo que se trate de un incumplimiento grave, ya que en este caso se aplica el mismo régimen de prescripción que para el vendedor.

Creemos que el principio de cumplimiento simultáneo de las obligaciones recíprocas con dicho carácter, no debería quedar restringido en su ejercicio por el plazo de prescripción establecido para las acciones edilicias. Sobre todo cuando el comprador actúa de buena fe.

Por ello, el Código Civil alemán en el parágrafo 478, y el Código Civil suizo en el artículo $210,2^{\circ}$, vienen a establecer que las excepciones por los defectos de la cosa, subsisten más allá del transcurso del plazo marcado para el ejercicio de las acciones si el comprador formuló la denuncia del defecto, o notificó éste al vendedor.

Esto significaría que el comprador, cuando actúa defendiéndose, dispone de plazos mayores para hacer valer el defecto que por vía de ataque, siempre, claro está, que la alegación de la excepción no sea sorpresiva y de mala fe, por lo que se exige que el comprador haya comunicado, en su momento, el defecto.

Ahora bien, en el Derecho no existe este matiz que permita dejar en una condición de igualdad de protección al vendedor y comprador, con lo cual, el tribunal difícilmente podrá alterar el régimen de prescripción establecido para las acciones edilicias. No obstante, creemos que sí es posible que el tribunal admita la exceptio non rite adimpleti contractus, aunque se encuentren prescritas las acciones que le permitan al comprador por vía reconvencional solicitar el cumplimiento. Si bien sabemos que lo correcto es oponer la exceptio acompañada de una demanda reconvencional, no sería justo que a la exceptio se aplique un régimen de prescripción tan breve.

Además el plazo de prescripción para esta defensa debe ser único y no variar según la acción que se ejercite en la demanda reconvencional. Es por esto, que creemos que el tribunal debería admitir su ejercicio en función 
del plazo de prescripción establecido en el artículo 1.964 del C.C. En este caso basta la negativa de cumplimiento por el cumplimiento defectuoso del vendedor, sin que haga falta una demanda reconvencional que justifique el ejercicio de la exceptio.

Por esto, creemos que deberá el excipens acreditar de forma irrefutable que ejerce de buena fe la exceptio, pues si no ocurre así, podría entender el tribunal que lo único que busca el comprador es impedir el cobro del precio del demandante. No se entendería que transcurrido un período de tiempo prolongado, el comprador nunca haya dicho algo sobre el defecto de la cosa comprada al vendedor.

\section{Algunas CONClusiones}

La doctrina y la jurisprudencia española distinguen entre dos tipos de excepciones: la genuina excepción de incumplimiento contractual, que se produce frente a una omisión total de la ejecución de la prestación por parte de quien reclama el cumplimiento de la contraprestación; y la excepción de contrato no cumplido adecuadamente, que es ejercitada cuando no se ha dado fiel cumplimiento a lo estipulado por las partes, existiendo un cumplimiento irregular o inoportuno.

La excepción de contrato no cumplido adecuadamente no procede para aquellas prestaciones de carácter intuitus personae, pues en este tipo de obligaciones, la consideración de la persona que debe realizar la prestación es fundamental; con lo cual no puede mirarse la prestación otorgada por una tercera persona distinta como un verdadero cumplimiento. Por lo tanto, no estaríamos ante un cumplimiento defectuoso, sino más bien ante un incumplimiento total de la prestación debida; debiéndose, por ende, ejercitar la excepción de contrato no cumplido.

En las obligaciones de medio o de actividad, el cumplimiento defectuoso no se pondera sólo analizando si el acreedor obtuvo el resultado esperado o no. Debiéndose tener en cuenta además la diligencia empleada por el deudor en la ejecución de la prestación. El éxito o no de la excepción, estará sujeta a si el deudor ha mantenido la diligencia y pericia debida que le exigía el cumplimiento de su obligación. Independientemente de si éste ha conseguido o no el resultado esperado por su acreedor. En efecto, para el éxito de la excepción de contrato no cumplido adecuadamente, el exicipens deberá acreditar que el incumplimiento del deudor se debe a la falta de la diligencia exigida en la ejecución de su actividad. Debiendo, por ende, existir falta del resultado esperado y ausencia de la diligencia exigida, para la obtención del resultado que se esperaba. 


\section{BiBLIOGRAFÍA}

Albaladejo, Manuel, Derecho civil (Barcelona, Bosch, 2002).

Asua González, Clara, Responsabilidad civil médica, en Reglero Campos, Luis Fernando (coordinador), Tratado de responsabilidad civil (Navarra, Aranzadi, 2006).

Beltrán de Heredia y Onis, Pablo, El incumplimiento de las obligaciones (Madrid, Edersa, Editoriales de Derecho Reunidas, 1990).

Bercovitz Rodríguez-Cano, Rodrigo, Comentarios al Código Civil (Navarra, Aranzadi, 2001).

Bustos VAldivia, Inmaculada, La suspensión del pago del precio en la compraventa (Valencia, Tirant lo Blanch, 1999).

Cabanillas Sánchez, Antonio, Las obligaciones de actividad y de resultado (Barcelona, Bosch, 1993).

Capitant, Henri, De la causa de las obligaciones (traducido y notas de Tarragato y Contreras, Madrid, Góngora, 1928).

De Cuevillas Matozzi, Ignacio, La relación de causalidad en la órbita de derecho de daños (Valencia, Tirant lo Blanch, 2000).

De Verda y Beamonte, José Ramón, Saneamiento por vicios ocultos (Valencia, Aranzadi, 2009).

Díez-Picazo, Luis, Fundamentos del Derecho civil patrimonial (Madrid, Editorial Civitas, 1996), II.

Enneccerus, Ludwing, Derecho de Obligaciones (15ª revisión por Henrich Lehmann, traducción de Blas Pérez González y José Alguer, 2a edición, Barcelona, Bosh, 1954-1999), II.

Espin Canovas, Diego, La excepción de incumplimiento contractual, en Anuario de Derecho Civil, 17 (1964).

Fernández Hierro, José Manuel, La "exceptio non adimpleti contractus", en Estudios de Deusto (1995).

Fernández Urzaineui, Francisco Javier, La regla de la simultaneidad en el cumplimiento de las obligaciones bilaterales, en Revista Critica Derecho Inmobiliario (1997).

García Amigo, Manuel, Teoría general de las obligaciones y contratos. Lecciones de derecho civil (Madrid, McGraw-Hill/Interamericana de España, 1995), II.

González Poveda, Pedro, Comentario al art. 1.486 C.C., en Sierra Gil de la Cuesta, Ignacio (coordinador), Comentario del Código Civil (Barcelona, Bosch, 2006), VII.

Hedemann, Justus Wilhelm, Tratado de Derecho civil (traducción de Jaime Santos Briz, Madrid, Revista de Derecho Privado, 1956), III.

Jordano Fraga, Francisco, Obligaciones de medios y resultados, en Anuario de Derecho Civil (1991).

LaCruz Berdejo, José Luis, Elementos de Derecho Civil (Madrid, Dykinson, 1999), II.

Larenz, Karl, Derecho de obligaciones (versión española y notas de Jaime Santos Briz, Madrid, Revista de Derecho Privado, 1958), I.

Llacer Matacás, María Rosa, El saneamiento por vicios ocultos en el Código civil: su naturaleza jurídica (Barcelona, Bosch, 1992).

Lовато Gómez, Jesús Miguel, Contribución al estudio de la distinción entre obligaciones de medios y las obligaciones de resultado, en Anuario de Derecho Civil (1992).

Martínez Calcerrada, Luis, Cumplimiento defectuoso de la prestación, en Revista Critica de Derecho Inmobiliario (1976). 
Orti Vallejo, Antonio, Los defectos de la cosa en la compraventa civil y mercantil (Granada, Comares, 2002).

Persico, Giovanni, L'eccezione d'inadempimento (Milano, Giuffrè, 1955).

Puig Brutau, José, Fundamentos de Derecho Civil (Barcelona, Bosch, 1988), I.

Reglero Campos, Luis Fernando, El nexo causal. Las causas de exoneración de responsabilidad: culpa de la víctima y fuerza mayor. La concurrencia de culpas, en REGLERO CAMpos, Luis Fernando (coordinador), Tratado de responsabilidad civil (Navarra, Aranzadi, 2006).

Rodríguez Grez, Pablo, Responsabilidad contractual (Santiago, Editorial Jurídica de Chile, 2003).

Rodríguez Marín, Concepción, Culpa de la víctima y responsabilidad sin culpa, en Revista de Derecho Privado, 76 (1992) 1.

Santos Briz, Jaime, Derecho civil: Teoría y práctica (Madrid, Edersa, 1973), IV.

Serra Rodríguez, Adela, La responsabilidad civil del abogado (Navarra, Aranzadi, 2000).

Traviesas, Miguel, Obligaciones reciprocas, en Revista de Derecho Privado, 192 (1929). YzQuierdo Tolsada, Mariano, La responsabilidad civil del profesional liberal (Madrid, Reus, 1989). 
